\title{
Cenários Climáticos e Produtividade do Algodão no Nordeste do Brasil. Parte II: Simulação Para 2020 a 2080
}

\author{
Fabrício Daniel dos Santos Silva ${ }^{1}$ (D), Rafaela Lisboa Costa $^{1}$ (D), \\ Rodrigo Lins da Rocha Júnior ${ }^{1}$ (D), Heliofábio Barros Gomes ${ }^{1}$ (D), Pedro Vieira de Azevedo ${ }^{2}$ (D), \\ Vicente de Paulo Rodrigues da Silva ${ }^{2}$ (D), Leonardo Amaral Monteiro ${ }^{3,4}$ \\ ${ }^{1}$ Instituto de Ciências Atmosféricas, Universidade Federal de Alagoas, Maceió, AL, Brasil. \\ ${ }^{2}$ Unidade Acadêmica de Ciências Atmosféricas, Universidade Federal de Campina Grande, \\ Campina Grande, PB, Brasil. \\ ${ }^{3}$ Departamento de Engenharia Agrícola, Universidade de Campinas, Campinas, SP, Brasil. \\ ${ }^{4}$ Department of Crop Sciences, Swedish University of Agricultural Sciences, Umeä, Sweden.
}

Recebido em: 6 de Julho de 2020 - Aceito em: 21 de Outubro de 2020

\begin{abstract}
Resumo
Este trabalho teve como objetivo principal gerar cenários climáticos futuros, e avaliar os impactos na produtividade do algodão herbáceo através de um modelo agrometeorólogico, quando comparada com a produtividade atual observada. Um downscaling estatístico foi empregado para obter as series futuras das variáveis meteorológicas necessárias para o cálculo da produtividade, obtido com um modelo agrometeorólogico devidamente calibrada para a realidade do algodão na região semiárida do Nordeste brasileiro. As series temporais das variáveis meteorológicas tiveram suas falhas devidamente preenchidas e passaram por um rigoroso sistema de controle de qualidade. As projeções futuras calculadas para os cenários climáticos A1B e A2, dos modelos ECHAM5-OM e HadGEM2-ES foram unanimes em apontar redução significativa das chuvas e aumento das temperaturas. A evapotranspiração, consequentemente, também apresenta tendência de aumento para o horizonte futuro estudado, de 2020 a 2080. Como impacto para a cultura do algodão, prevê-se, para 23 municípios estudados do semiárido nordestino, redução significativa da produtividade, que pode ser reduzida a aproximadamente metade da produtividade atual observada.
\end{abstract}

Palavras-chave: modelo agrometeorológico, downscaling estatístico, produtividade do algodão.

\section{Climate Scenarios and Cotton Yield in Northeast Brazil. Part II: Simulation for 2020 to 2080}

\begin{abstract}
This paper had as its primary objective the generation of future climatic scenarios and the evaluation of impacts over the productivity of upland cotton through an agrometeorological model, when compared to the current productivity observed. A statistical downscaling was used to obtain the future series of meteorological variables needed for the calculation of productivity, obtained with an agrometeorological model appropriately calibrated for the reality of cotton in the semi-arid region of Northeast Brazil. The time series of the meteorological variables had their flaws properly completed and went through a rigorous quality control system. The future projections calculated for the climatic scenarios A1B and A2, of the models ECHAM5-OM and HadGEM2-ES were unanimous in pointing out the significant reduction in rainfall and temperature rising. The evapotranspiration, consequently, also presents an upward trend for the future horizon studied, from 2020 to 2080 . As impact for the cotton crop, is predicted, for the 23 studied municipalities of the northeast semi-arid, a significant reduction in productivity, which can be reduced to approximately half of the current observed productivity.
\end{abstract}

Keywords: agrometeorological model, statistical downscaling, cotton yield.

Autor de correspondência: Fabrício Daniel dos Santos Silva, fabricio.santos@.cat.ufal.br. 


\section{Introdução}

O clima evolui ao longo do tempo sob a influência de três fatores centrais: sua própria dinâmica interna, os forçamentos externos naturais, como erupções vulcânicas e variações solares, e os forçamentos antrópicos, devido às atividades humanas, como a emissão de gases de efeito estufa por meio da queima de combustíveis fósseis, e pelo desmatamento. No sistema climático, todos estes elementos estão interligados e o desequilíbrio de uma parte influencia no equilíbrio dos demais (Ghil, 2002).

Diversos estudos, principalmente a partir das últimas décadas após o surgimento do IPCC, em 1988, vêm tentando demonstrar que as mudanças nos padrões climáticos já são evidentes em todo o planeta (Gomez, 1999; Frich et al., 2002; Kürbis et al., 2009; Solman et al., 2008). Haylock et al. (2006) estudaram dados diários de temperatura máxima e mínima para estações localizadas em oito países da América do Sul, e concluíram que as tendências de aumento mais importantes foram encontradas nas séries de temperaturas mínimas, com uma tendência de aumento de noites quentes durante o verão.

Em particular para a região Nordeste do Brasil (NEB), o estudo recente de Costa et al. (2020), demonstrou não apenas predominância de tendências positivas para índices de temperatura, como padrões bem organizados de tendências de aumento/diminuição da precipitação total no NEB. Estes resultados corroboraram a evolução de aumento das temperaturas detectada por Marengo et al. (2009), muitas vezes associadas a episódios frequentes de secas que podem se intensificar no futuro (Marengo et al., 2016). Para a agricultura de subsistência, especialmente a de sequeiro, a combinação de aumento das temperaturas e diminuição da amplitude térmica provoca diretamente aumento da evapotranspiração potencial (ETP) (Greve et al., 2014), com exceção de áreas vizinhas a grandes corpos d'água e/ou áreas irrigadas, como demonstrado em Cabral Júnior et al. (2019). No caso do NEB, que tem a maior parte de sua área inserida no clima semiárido, o aumento na ETP associado a já conhecida alta variabilidade espaçotemporal da precipitação, pode prejudicar ainda mais as atividades agrícolas, notadamente as de sequeiro, como no caso do cultivo do algodão herbáceo.

A cultura do algodão herbáceo já foi a mais importante e rentável prática agrícola do Nordeste brasileiro, que já chegou a plantar mais de um milhão de hectares, como na safra 1984/85. Pragas e adversidades climáticas sempre foram fatores limitantes da produção. Com o avanço no controle das pragas, o fator climático torna-se o mais importante ator para o sucesso ou fracasso das safras, tendo em vista que a maior parte da produção é sob regime de sequeiro.

Diante das discussões climáticas atuais, com projeções futuras para a região muitas vezes preocupantes, fazse necessário um estudo aprofundado de como determina- dos cenários futuros de mudanças climáticas poderá impactar o sistema produtivo. Desta forma, o foco desta pesquisa será trazer para o nível local de municípios produtores de algodão no NEB, projeções climáticas futuras por meio da técnica de downscaling estatístico aplicado aos cenários climáticos A1B e A2 de dois modelos climáticos globais (MCGs), e estimar a produtividade desta cultura no horizonte de 2020 a 2080, a partir de um modelo agrometeorológico calibrado e descrito na Parte I desta pesquisa.

\section{Material e Métodos}

\subsection{Dados, área de estudo e modelo agrometeorológico}

Os dados meteorológicos e de produtividade, disponibilizados pelo Instituto Nacional de Meteorologia (INMET) e pelo Sistema IBGE de Recuperação Automática (SIDRA) do Instituto Brasileiro de Geografia e Estatística (IBGE), foram descritos na Parte I desta pesquisa, assim como todo o processo de calibração e validação do modelo agrometeorológico. Este mesmo modelo foi utilizado para estimar a produtividade futura do rendimento do algodão herbáceo, a partir dos cenários climáticos regionalizados cuja metodologia é explicada a seguir.

\subsection{Modelos climáticos globais (MCG) e cenários de mudanças climáticas}

Um MCG procura representar matematicamente o sistema climático baseado nas propriedades físicas de seus componentes, mas em geral ainda deixam de representar características importantes em escala subgrade, como nuvens e topografia, devido a sua baixa resolução espacial, em média, da ordem de $250 \mathrm{~km}$ na horizontal, com 20 níveis na vertical (Sampaio e Silva Dias, 2014). Os MCGs evoluíram muito desde a criação do IPCC (Intergovernmental Panel on Climate Change) em 1988, passando a produzir projeções climáticas futuras incorporando informações de estimativas de gases de efeito estufa. Tais projeções, ou como são mais conhecidos, cenários futuros, são prognósticos das condições futuras do clima sob determinados padrões de emissões de gases de efeito estufa, como a duplicação do gás carbônico, monóxido de carbono, oxido nitroso, dióxido de enxofre, metano, entre outros gases (Mitchell e Hulme, 1999; Nakicenovic et al., 2000; Jones et al., 2004).

Os cenários futuros foram o A1B e A2, divulgados pelo Special Report Emissions Scenarios (SRES), no quarto relatório do IPCC. O cenário Al representa um futuro de rápido crescimento econômico e não sustentável, 
populações ainda não estabilizadas e rápida introdução de tecnologias mais eficientes, com redução significativa das diferenças de renda entre as populações ricas e pobres. $\mathrm{O}$ cenário A1 se divide em três: uso intensivo de combustíveis fósseis (A1FI), fontes não fósseis (A1T) ou um equilíbrio entre as fontes (A1B). O cenário A1B é considerado o mais realista entre todos os cenários (Raskin et al., 2005). O cenário $A 2$ representa um mundo fragmentado, não sustentável, e heterogêneo entre regiões e nações, com altos índices de população e menos interesse em rápido crescimento econômico (SRES, 2010). Entre os cenários é considerado o mais pessimista (Sheffield et al., 2008).

Os MCGs usados foram o ECHAM5-OM, do Max Planck Institute for Meteorology, da Alemanha (Marsland et al., 2003; Raddatz et al., 2007); o HadGEM2-ES, do Meteorological Office Hadley Centre, do Reino Unido (Bellouin et al., 2007; Collins et al., 2008). O ECHAM5-OM consiste do acoplamento de um MCG atmosférico (ECHAM5) e de uma componente oceano-gelo marinho.

O ECHAM5 é a quinta geração do modelo ECHAM, evoluindo originalmente do modelo de previsão de tempo espectral do Centro Europeu de Previsão de Tempo a Médio Prazo (ECMWF). Seu módulo oceânico é um modelo de equações primitivas (Grade-C, coordenadas-Z, superfície livre), com os pressupostos hidrostáticos e de Boussinesq. Ele inclui um modelo de gelo marinho dinâmico/ termodinâmico com uma reologia plástico-viscosa e um esquema de camada limite inferior para o fluxo ao longo de topografia íngreme. Suas variáveis prognosticas atmosféricas são a vorticidade, divergência, temperatura, pressão, vapor d'água, água liquida de nuvens e gelo de nuvens. Sua resolução espacial é de 63 níveis de resolução horizontal e 31 níveis de resolução vertical. Resolução oceânica de $1,5^{\circ}$, com 40 níveis.

O HadGEM2-ES é um modelo acoplado do sistema terrestre utilizado pelo MetOffice Hadley Centre para simulações ao longo do século. Este foi o primeiro modelo do Hadley Centre a incluir os componentes padrões do sistema terrestre. Este módulo é utilizado por um grande número de instituições no mundo, tanto para previsão do tempo operacional quanto para pesquisas climáticas. Este modelo compreende um MCG atmosférico com 96 níveis de resolução horizontal e 38 níveis de resolução vertical, e um MCG oceânico com resolução horizontal de $1^{\circ}$ (aumentando até $0,33^{\circ}$ no equador) e 40 níveis verticais. Os principais componentes do sistema terrestre incluídos são os ciclos do carbono terrestre e oceânico, e a química troposférica. Um modelo dinâmico de vegetação terrestre está presente, simulando a cobertura e balanço do carbono para cinco tipos de vegetação (árvores folhosas, árvores pouco folhosas, gramas $\mathrm{C} 3$, gramas $\mathrm{C} 4$ e arbustos). A biologia e a química dos carbonatos oceânicos são representadas, incluindo a limitação do crescimento do plâncton por macro e micronutrientes.

\subsection{Downscaling estatístico}

O downscaling estatístico é um campo da ciência que permite relacionar os cenários de mudanças climáticas globais fornecidas pelos MCGs com observações históricas de variáveis de superfície locais, como a precipitação ou temperatura de estações meteorológicas em uma região de interesse (Timbal et al., 2003; Hewitson e Crane, 1996; Timbal e Jones, 2008; Benestad, 2010; Brands et al., 2011a; Brands et al., 2011b; Gutzler e Robbins, 2011).

Um modelo de downscaling estatístico (MDE) geralmente é construído por meio de uma função de transferência $R=F(L)$, com $R$ sendo a resposta local (por exemplo, precipitação, temperatura ou evapotranspiração obtidas de uma determinada estação meteorológica), e $F$ uma função determinística/estocástica condicionada por $L$, obtida a partir da relação empírica obtida da respectiva grade associada ao MCG utilizado.

O MDE escolhido para a geração das séries dos respectivos cenários foi o método dos análogos. Este método tem sido aplicado essencialmente no campo da previsão do tempo (Lorenz, 1969; Kruizinga e Murphy, 1983), e na previsão do clima a curto prazo (Barnett e Preisendorfer, 1978; Van Den Dool, 1994). Para fins de redução de escala, este método ainda é pouco aplicado (Zorita et al., 1995; Cubasch et al., 1996; Biau et al., 1999, Zorita e Storch, 1999), embora a sua metodologia seja simples. A circulação atmosférica em grande escala simulada por um MCG é comparada com cada uma das observações históricas, representadas em uma grade comum de conjuntos de reanálises, e o padrão mais semelhante com o observado na reanálise é escolhido como seu análogo, com esta relação podendo ser imposta as observações realizadas por estações meteorológicas de superfície. O clima local observado simultaneamente é, então, associado ao padrão de grande escala simulado.

Nesta pesquisa a relação entre preditores (variáveis de grande escala) e preditandos (variáveis de superfície representadas em reanálises) foi estabelecida empiricamente no mesmo espaçamento de grade dos MCGs, neste caso, 2,5 $\times 2,5^{\circ}$ (Flato et al., 2013; Collins et al., 2013; Hartmann et al., 2013). Os preditores dos MCGs mais bem correlacionados com a precipitação oriunda da reanálise do projeto ERA40 (Uppala et al., 2005) foram as componentes zonal e meridional da velocidade média do vento no nível de $850 \mathrm{hPa}$, umidade especifica no nível de $850 \mathrm{hPa}$, pressão ao nível médio do mar, geopotencial em $500 \mathrm{hPa}$ e temperatura no nível de $850 \mathrm{hPa}$, Para a temperatura, utilizou-se reanálises do NCEP/NCAR (Kalnay et al., 1996; Brands et al., 2012) e os preditores mais bem correlacionados foram a umidade especifica no nível de $850 \mathrm{hPa}$, pressão ao nível médio do mar, geopotencial em $500 \mathrm{hPa}$ e temperatura no nível de $850 \mathrm{hPa}$.

Uma vez que a cadeia Preditores $\rightarrow$ Preditandos $\rightarrow$ MDE tenha sido concluída, os MDEs estarão prontos para 
ser utilizados e aplicados a qualquer um dos MCGs para a geração das séries temporais das estações de superfície em um horizonte futuro, para qualquer cenário de mudança climática (Gutierrez et al., 2013).

Foram geradas, a partir desta metodologia, séries temporais diárias das variáveis precipitação, temperaturas máximas e mínimas de 23 estações meteorológicas localizadas no NEB, com dados disponíveis de produtividade do algodão. Como o passo de tempo de entrada dos dados no modelo agrometeorológico descrito na Parte I deste trabalho é decendial, o período histórico comum para preditores (reanálises) e preditandos (observações), foi dividido em treinamento $(75 \%$ dos dados, relativo ao período climatológico de referencia 1961-1990) e testes (25\% dos dados, relativo ao período de observações 1991-2000). A fase de calibração do MDE é realizada utilizando os dados de treinamento, enquanto que a fase de testes é validada entre as simulações feitas para um período independente e comparado as observações. Os dados dos testes não são utilizados na fase de calibração, desta forma os coeficientes obtidos para o método dos análogos na fase de calibração podem ser extrapolados para novos conjuntos de dados provenientes dos cenários dos modelos, que nesta pesquisa foi para o horizonte 2020-2080.

\subsection{Análise da calibração do MDE e métricas de validação}

Uma das etapas mais importantes para inferir confiabilidade nos cenários futuros é analisar se o MDE é capaz de simular bem o ciclo anual climatológico. Esta comparação foi feita por meio de gráficos comparativos entre a climatologia observada no período de referencia 19611990 de cada estação e a climatologia obtida das previsões de cada modelo. As medidas de verificação relativas ao período de treinamento foram obtidas comparando as médias decendiais observadas e simuladas o obtendo-se e calculando-se as respectivas métricas:

(1) PDFescore: O PDFescore mede a sobreposição entre as funções de densidade de probabilidade empíricas observadas e previstas. Varia no intervalo [0,1]. Pontuação perfeita: 1. Este índice é descrito como em Perkins e McAneney (2007):

$$
\text { PDFescore }=\sum_{i=1}^{200}\left(P D F_{p i}-P D F_{o i}\right)
$$

onde $P D F_{f i}$ é a densidade de probabilidade das previsões e o $P D F_{o i}$ é a densidade de probabilidade das observações, para 200 classes definidas para toda a gama de observações e previsões. A densidade de probabilidade para cada classe é estimada por um filtro de Kernel em uma abordagem não paramétrica para encaixe das densidades. Todas as densidades são comparadas para cada classe, por um parâmetro de largura otimizado para distribuições nor- mais. O PDFescore é pouco sensível a falhas nas caudas das distribuições. No caso da precipitação diária, devido à alta densidade de probabilidade de classes localizadas próximas a zero, este índice é calculado apenas para a parte continua das distribuições, considerando-se exclusivamente os dias com chuva observada e prevista.

(2) Diagramas de dispersão: Observações no eixo $\mathrm{x}$ versus as previsões no eixo y são plotados em nuvem de pontos a fim de observar a possível relação entre duas variáveis e, dessa forma, mostrar de forma gráfica os pares de dados numéricos e sua relação. Associado ao diagrama, calculou-se o coeficiente de correlação de Pearson, que mede a força da relação linear entre observações e previsões. Varia entre $[-1,1]$. Pontuação perfeita: 1. O coeficiente de correlação de Pearson entre duas variáveis (observações $(o)$ e previsões $(p)$ ) é definida como a covariância das duas variáveis $(\operatorname{Cov}(\mathrm{o}, \mathrm{p}))$ dividida pelo produto de seus desvios-padrão (Eq. (2)), e o teste $t$-Student (Huang e Paes, 2009) foi aplicado para obter o valor crítico a partir do qual a correlação é estatisticamente significante a um nível de confiança de $95 \%$ e $99 \%$ :

$$
r_{o, p}=\frac{\operatorname{Cov}(o, p)}{\sigma_{o}}
$$

(3) Q-Q Plot: O gráfico quantil-quantil plot ou q-q plot é utilizado para determinar se dois conjuntos de dados pertencem a mesma distribuição de probabilidades. Em tais gráficos os pontos são formados pelos quantis amostrais e se no resultado os pontos alinham-se numa reta de inclinação 1, as distribuições das duas amostras podem ser consideradas as mesmas.

Outras métricas simples foram calculadas para fins de comparação entre as previsões e as observações do período de treinamento, como as médias e desvios-padrão de cada conjunto.

\subsection{Refinamento estatístico para downscaling da pressão atmosférica, umidade relativa, velocidade do vento e insolação à superfície.}

Os MDEs conhecidos, seus softwares e metodologias, são comumente preparados para dados de precipitação, temperaturas máximas e mínimas. Fez-se também necessário nesta pesquisa, adotar uma metodologia para redução de escala de outras variáveis importantes para o cálculo da ETP pelo método de Penman-Monteith, que são a pressão atmosférica $(P A t)$, a umidade relativa $(U R)$, e a velocidade média do vento (VMV). Tais dados são disponibilizados em arquivos no formato NETCDF, pelo Centro de Distribuição de Dados do IPCC, em pontos de grade para diversos modelos, para o período de janeiro de 2000 a dezembro de 2100 . Tais dados podem ser acessados no link: (http://www.ipcc-data.org/sim/gcm_monthly/ SRES_AR4/index.html). 
Foram extraídas as seguintes variáveis dos modelos ECHAM5-OM e HadGEM2-ES: PAt ao nível do mar, umidade relativa no nível de $850 \mathrm{hPa}\left(u r_{-} 850\right)$, e as componentes zonal (u_sup) e meridional do vento a superfície ( $v \_s u p$ ), para os respectivos pontos de grade mais próximos de cada uma das 23 estações meteorológicas. Um período em comum entre observações e saídas dos modelos, de janeiro de 2001 a dezembro de 2012, foi usado para um refinamento estatístico que permitisse transpor as estimativas dos modelos para o mesmo nível local das observações. Para exemplificar esta metodologia, consideremos que $u r_{-} 850(t)$ é a série temporal das previsões de uma caixa de grade do modelo ECHAM5-OM da $U R$ no nível de $850 \mathrm{hPa}$ e $u r \_o b s(t)$ é a série temporal da $U R$ observada em determinada estação, localizada dentro desta mesma caixa de grade. $\mathrm{O}$ erro da previsão da umidade relativa será definido como (Eq. (3)):

$$
\Delta U R_{t}=U R 850_{t}-U R o b s_{t}
$$

Neste caso, para cada $\mathrm{t}=1,2,3, \ldots \mathrm{N}$, uma série de diferenças é obtida, permitindo uma correção, para cada mês, de um erro médio obtido, ou viés (BIAS), dado por (Eq. (4)):

$$
B I A S=\frac{1}{N} \sum_{i=1}^{N} \Delta U R_{t}
$$

onde $N$ é o número total de previsões corrigidas em relação às observações, para cada mês.

Os valores modelados em cada mês para a variável são corrigidos pela compensação das médias das diferenças com as observações em cada mês. A nova série modelada para um ponto de estação corresponde agora com mais fidedignidade aos valores observados no período de validação, e este viés de correção é aplicado então a todo o restante da série de $U R$ do modelo, até o ano de 2080. A mesma metodologia é aplicada as séries de PAt. Como os modelos não estimam diretamente a $V M V$ a superfície, mas sim suas componentes zonal e meridional, a velocidade média é estimada pela Eq. (5), e em seguida a mesma metodologia de redução das diferenças pelo BIAS é aplicada.

$$
V \text { sup }=\left(u \_ \text {sup }^{-2}+v \_s u p^{-2}\right)^{0,5}
$$

Por fim, têm-se os valores mensais modelados destas variáveis para o período 2000 a 2100. Desta forma, para o cálculo dos cenários futuros da ETP para 2020-2080, período foco desta pesquisa, assume-se que para as variáveis $P A t, U R$ e $V M V$, os três decêndios terão o valor mensal, que é uma aproximação bastante razoável para três variáveis de natureza contínua.
A última variável necessária ao cálculo da ETP e que não possui nenhum tipo de saída de MCG é a insolação. Neste caso, de posse dos dados acumulados decendialmente para TMax e TMin, e consequentemente TMed, e agora de posse de estimativas decendiais da PAt, UR e $V M V$, pode-se criar séries de insolação utilizando uma técnica de imputação multivariada disponibilizada no pacote estatístico MICE, desenvolvido em linguagem $\mathrm{R}$ (Van Buuren e Groothuis-Oudshoorn, 2011; Costa et al., 2012; Costa et al., 2020). Para tanto, as observações do período 1961-2000 de cada estação são agregadas aos valores modelados a partir de 2001, restando apenas a insolação como dado faltante a ser gerado, pela relação direta com as demais variáveis. $\mathrm{O}$ reconhecimento de padrões associados a estas médias relativas ao período de 1961 a 2000 são essenciais para a estimativa dos valores decendiais.

\section{Resultados e Discussões}

\subsection{Calibração e validação do método de downscaling estatístico (MDE) para precipitação e temperatura}

A Fig. 1 mostra, para uma amostra de oito das vinte e três estações: Balsas (MA), Paulistana (PI), Apodi (RN), Quixeramobim (CE), Monteiro (PB), Ouricuri (PE), Água Branca (AL) e Correntina (BA), que as normais climatológicas observadas versus as médias climatológicas mensais obtidas com os modelos no período de calibração 1961-1990 são muito coincidentes, evidenciando a habilidade do MDE em representar bem o ciclo anual da precipitação. Observou-se em estações localizadas no norte do NEB tendência dos modelos em subestimar a precipitação entre março e abril. Este viés seco concorda com os resultados obtidos por Alves et al. (2005), que em seu estudo mostraram que a versão ECHAM4.5 subestimava a precipitação da quadra chuvosa do norte da região Nordeste: fevereiro a maio, o mesmo ocorrendo, em maior magnitude, com o modelo HadGEM2-ES.

Para as temperaturas máximas e mínimas, as Figs. 2 e 3 mostram, a título de exemplo, a normal climatológica observada versus as medias climatológicas mensais obtidas com os modelos para quatro estações: Água Branca (AL), Balsas (MA), Quixeramobim (CE) e Senhor do Bonfim (BA). Assim como para a precipitação, as normais foram coincidentes, refletindo a habilidade dos modelos em simular bem as temperaturas a superfície.

A Fig. 4 mostra para a precipitação decendial de duas localidades Bom Jesus da Lapa (BA) e Sobral (CE), três gráficos com diferentes parâmetros estatísticos calculados no período de validação 1991-2000: Funções densidade de probabilidade (FDP) com o cálculo do respectivo 

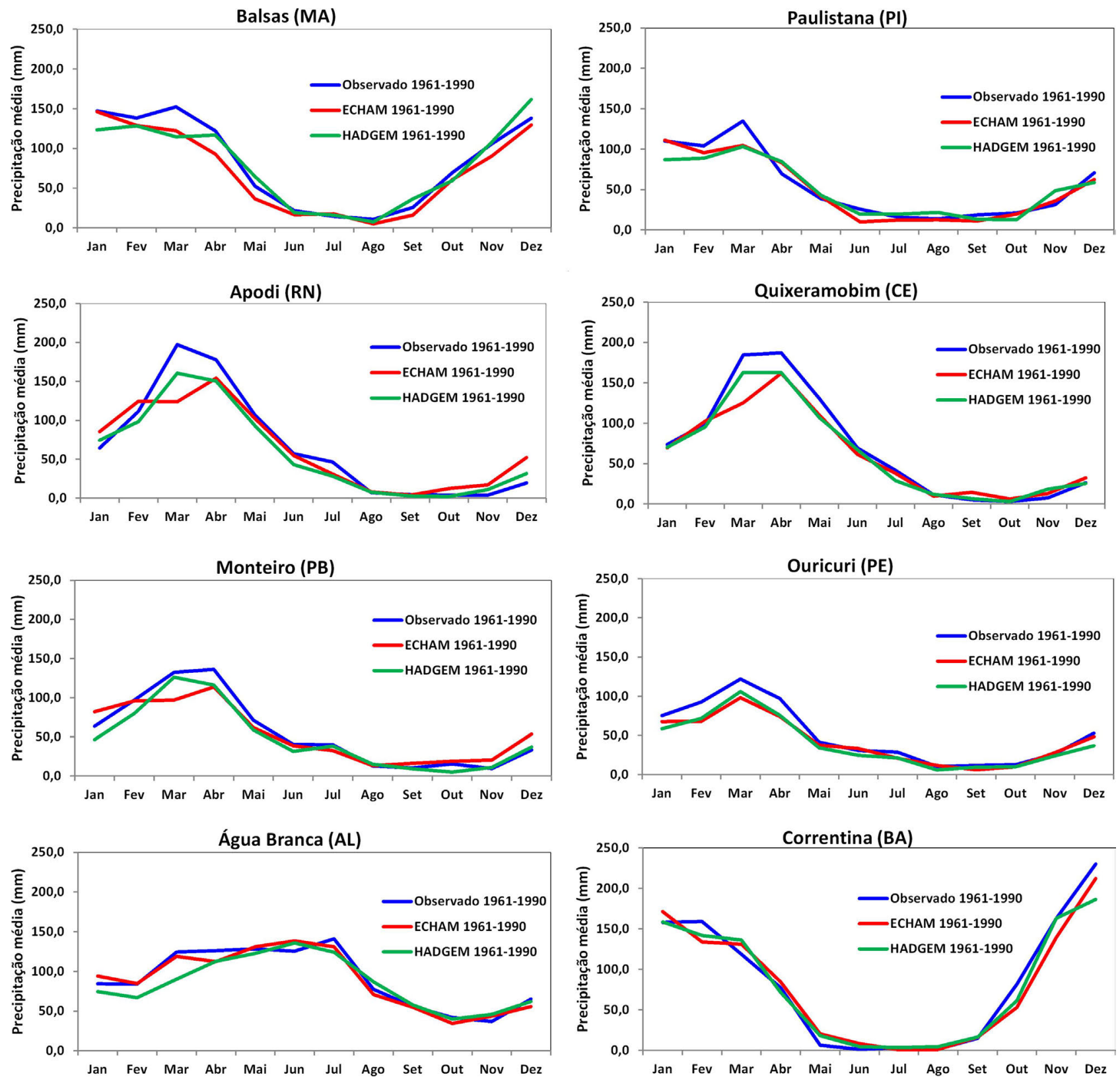

Figura 1 - Climatologia da precipitação do período 1961-1990, com dados observados (linha azul), modelos ECHAM5-OM (linha vermelha) e HadGEM2-ES (linha verde), para oito das 23 estações utilizadas nesta pesquisa.

PDFescore, diagrama de dispersão entre valores previstos e observados, com respectivo valor da correlação $r$, e um gráfico $Q-Q$ plot dos percentis previstos e observados que sugere o grau de normalidade dos percentis estimados. Para Bom Jesus da Lapa e Sobral nota-se o comportamento similar das curvas PDF, com respectivos $P D F e-$ score iguais a 0,92 e 0,79 .

Os diagramas de dispersão mostram que a maior parte dos valores acumulados situa-se numa faixa de até $100 \mathrm{~mm}$. A habilidade de prever melhor ou não os extremos reflete significativamente nos valores de $r$, mesmo que os demais gráficos e medidas indiquem confiança para se usar os dados previstos. Neste período de validação de dez anos, agregados de 10 dias correspondem a 360 decêndios. Para este tamanho $n=360$, as correlações apresentam significância estatística ao nível de $99 \%$ de confiança se forem maiores que 0,29 . Das 23 estações, em 15 os valores de $r$ foram superiores a 0,50 , com 4 delas apresentando $r$ acima de 0,70, incluindo-se Bom Jesus da Lapa e Sobral mostradas na Fig. 4. Em apenas 5 estações, os valores de $\mathrm{r}$ foram abaixo de 0,40, em Água Branca $(r=0,32)$, Lençóis $(r=0,38)$, Monteiro e Vitória da Conquista $(r=0,39)$ e Balsas $(r=0,34)$, mesmo assim, superiores ao valor limite de 0,29 , podendo-se afirmar que 

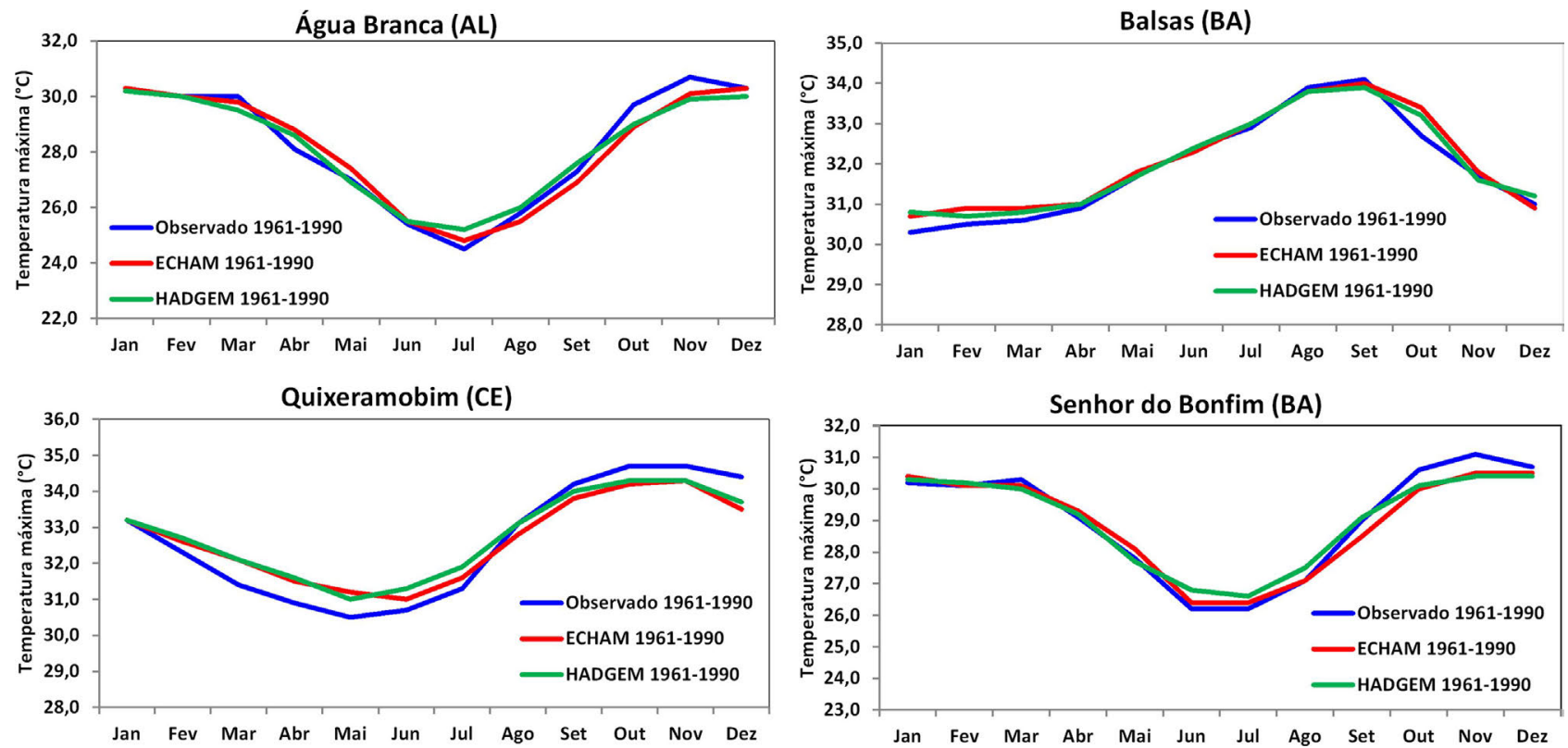

Figura 2 - Climatologia da temperatura máxima do período 1961-1990, com dados observados (linha azul), modelos ECHAM5-OM (linha vermelha) e HadGEM2-ES (linha verde), para 4 estações.
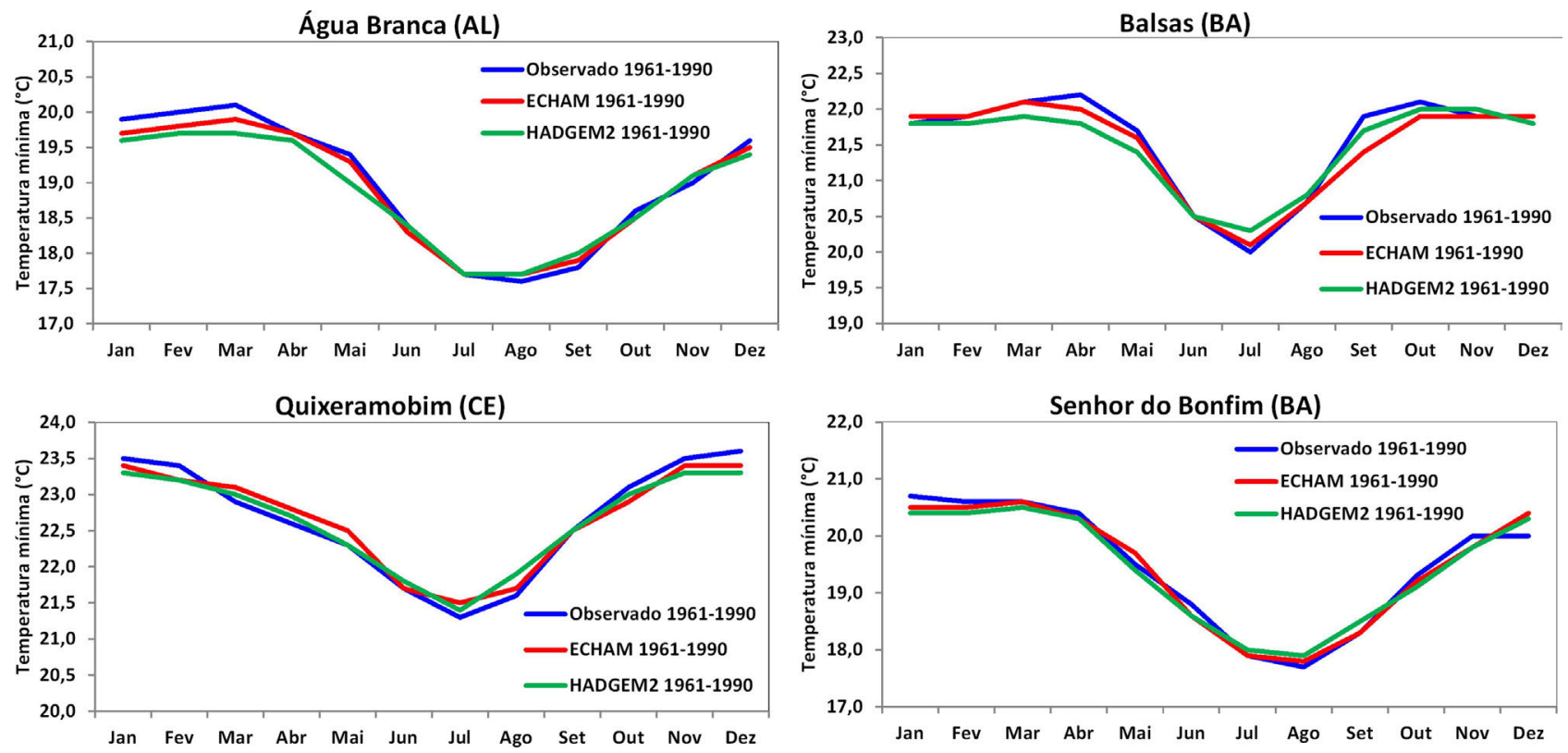

Figura 3 - Climatologia da temperatura mínima do período 1961-1990, com dados observados (linha azul), modelos ECHAM5-OM (linha vermelha) e HadGEM2-ES (linha verde), para 4 estações.

todas as previsões apresentam significância estatística em relação as observações.

Os gráficos $Q-Q$ plot de todas as estações mostram que os percentis empíricos calculados para as observações e previsões geram retas muito próximas da reta diagonal que indica uma distribuição quantílica perfeita. Em muitos casos, os valores extremos aparecem destaca- dos e devido a ineficácia de suas previsões, ditam o desvio das retas empíricas, mas sem colocar sob suspeita a hipótese de normalidade das distribuições dos percentis calculados.

Para as temperaturas máximas e mínimas, as Figs. 5 e 6 mostram, a título de exemplo para as duas estações que apresentaram os maiores valores de correlação entre pre- 

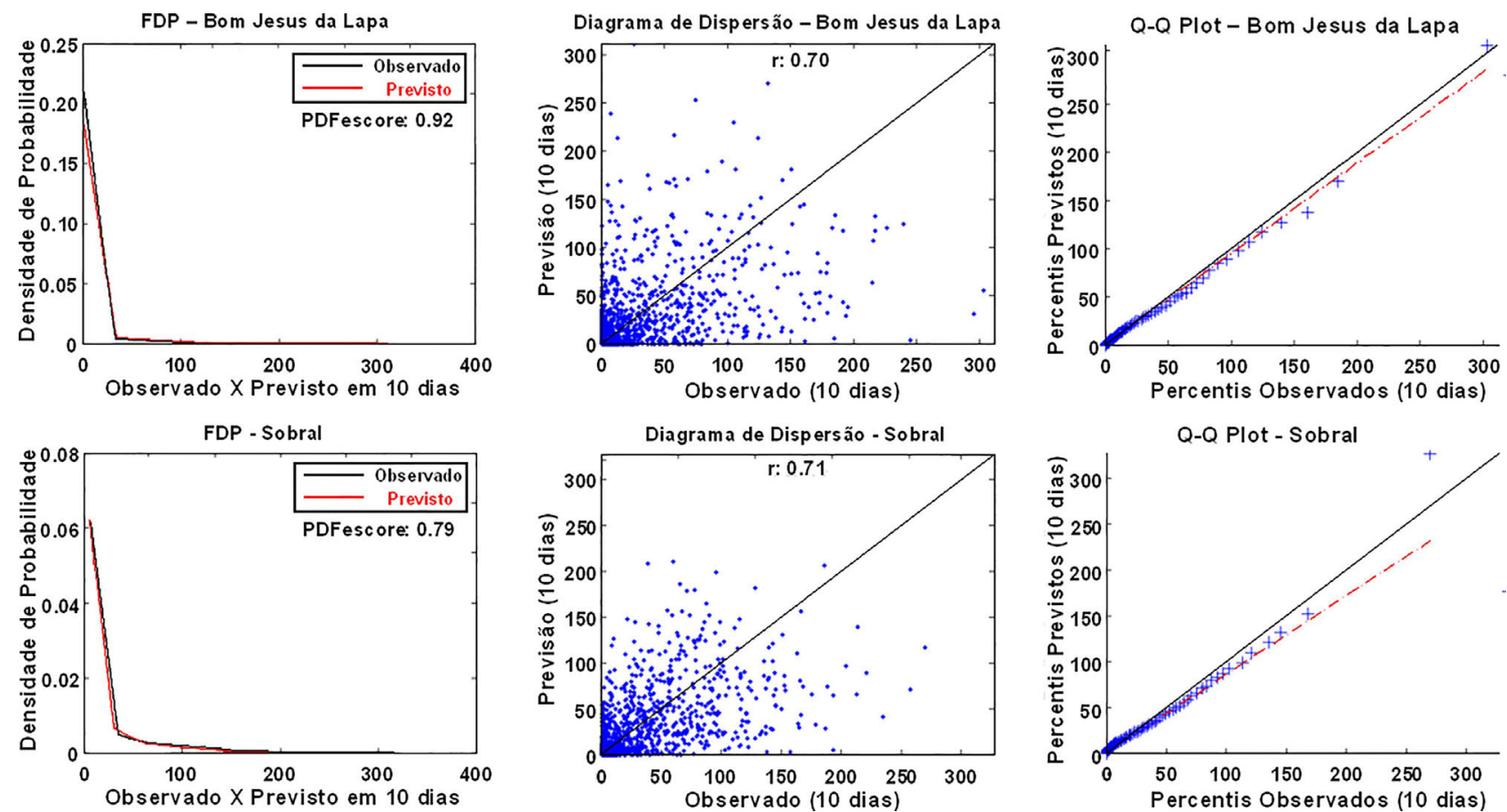

Figura 4 - Para cada estação, funções densidade de probabilidade e valores do PDFescore à esquerda, diagramas de dispersão e valores de $r$ no centro, e distribuições $Q-Q$ plot a direita, para as precipitações observadas e previstas acumuladas (mm) em 10 dias para o período $1991-2000$.
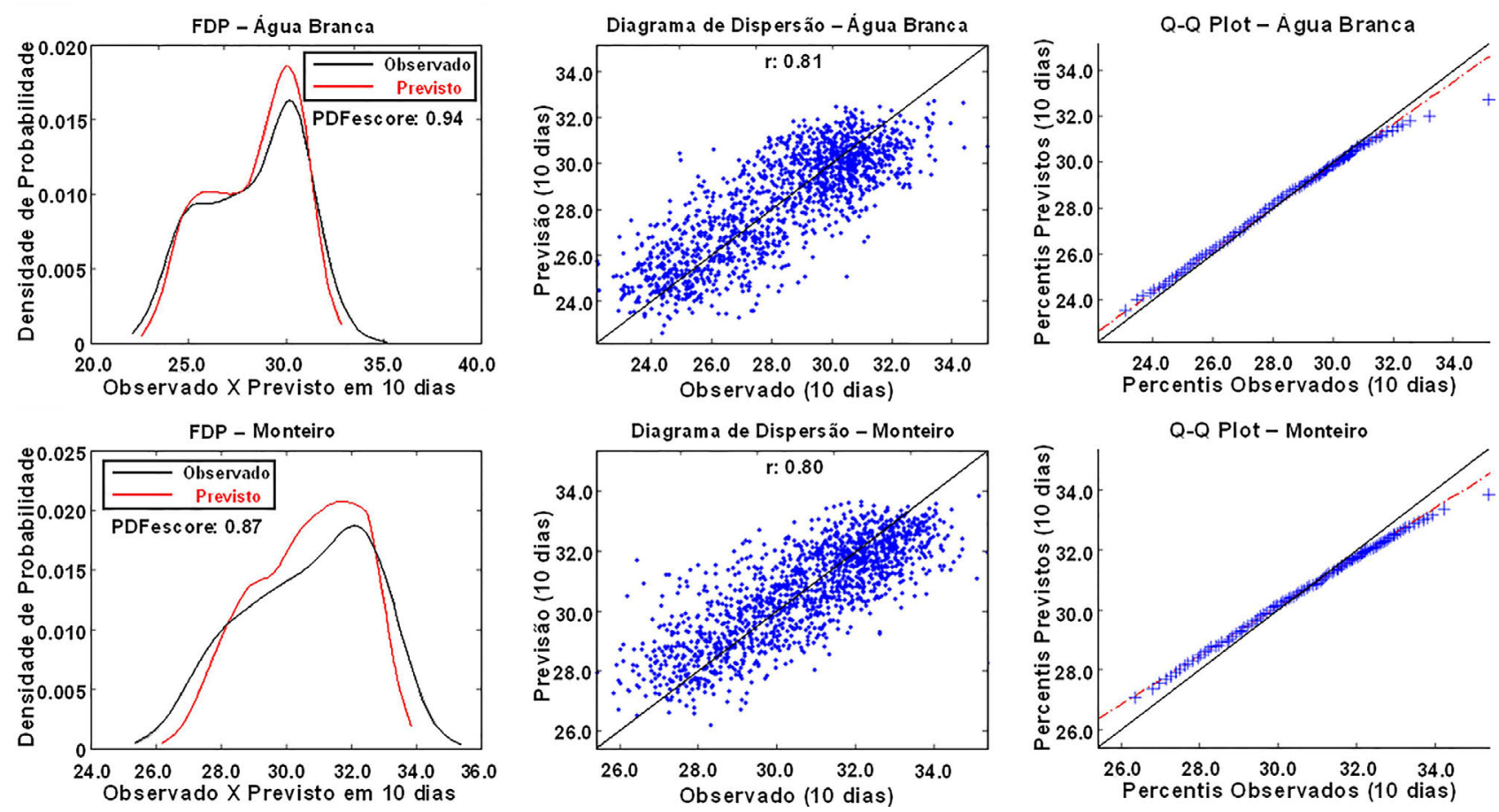

Figura 5 - Mesmo que a Fig. 4, mas para temperaturas máximas das estações de Água Branca (AL) e Monteiro (PB).

visões e observações, as funções densidade de probabilidade e valores do PDFescore à esquerda, diagramas de dispersão e valores de r no centro, e distribuições $Q-Q$ plot a direita, para valores agregadas de 10 dias no período
1991-2000. As curvas PDF mostram uma leve distribuição bimodal, enquanto os diagramas de dispersão mostram valores bem ajustados em torno da diagonal principal, referendadas pelas retas dos percentis empíricos muita 

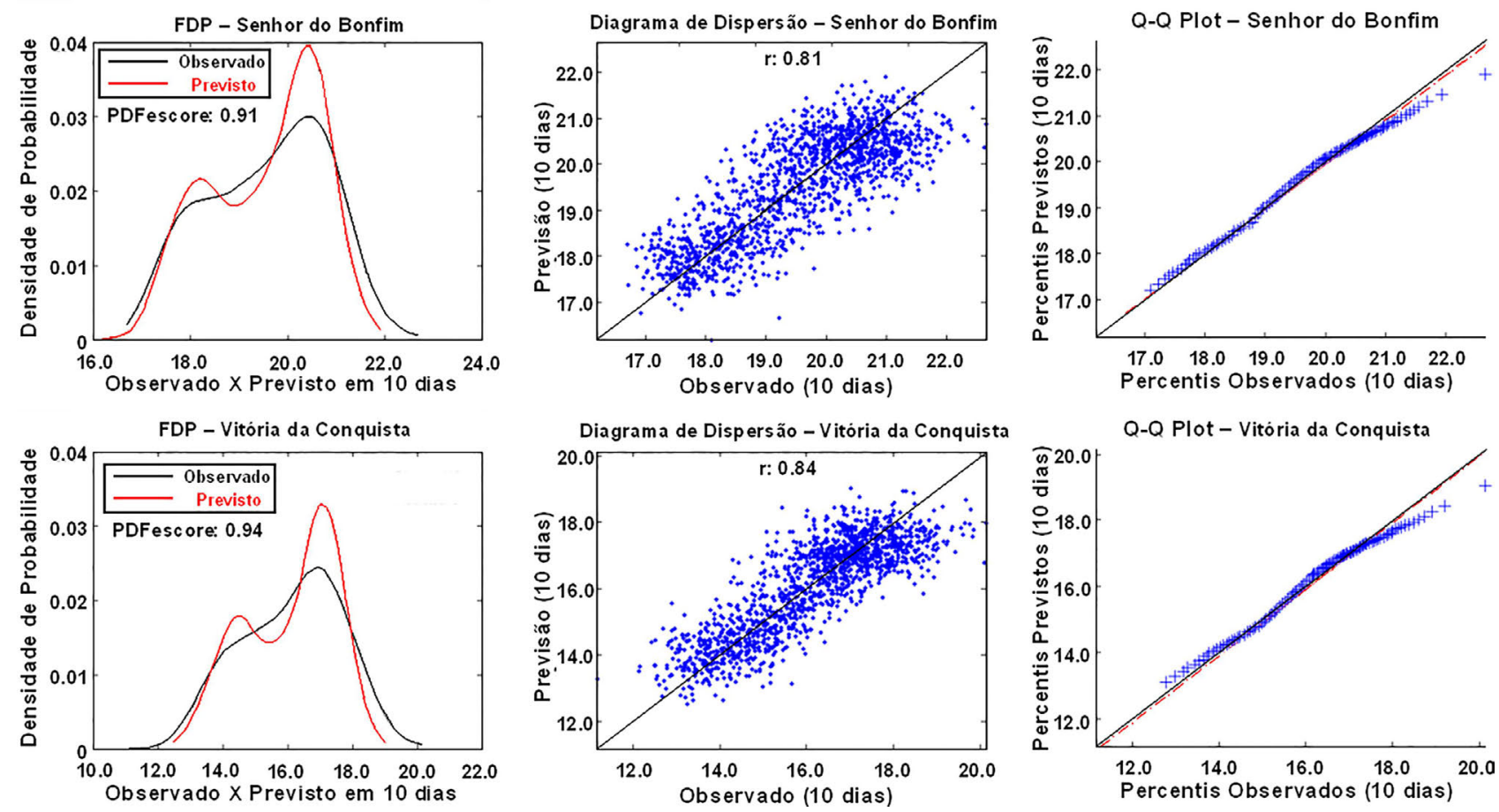

Figura 6 - Mesmo que a Fig. 4, mas para temperaturas mínimas das estações de Senhor do Bonfim (BA) e Vitória da Conquista (BA).

próxima da reta diagonal indicando uma distribuição quantílica ótima.

\subsection{Cenários futuros da precipitação, temperaturas máximas e mínimas}

Para o cenário A1B, a Fig. 7 mostra as diferenças obtidas dos modelos ECHAM5-OM e HadGEM2-ES para a precipitação (a e b), temperaturas máximas (c e d) e temperaturas mínimas (e e f). Em termos médios das 23 estações estudadas, o modelo ECHAM5-OM para o cenário A1B prevê uma redução média de $-29,88 \%$ da precipitação, e aumentos de $1,3{ }^{\circ} \mathrm{C}$ para temperaturas máximas, e $1,4{ }^{\circ} \mathrm{C}$ para temperaturas mínimas, até o final de 2080 . O modelo HadGEM2-ES prevê uma redução média de $-46,87 \%$ da precipitação, e aumentos de $1,5{ }^{\circ} \mathrm{C}$ para temperaturas máximas, e $1,3{ }^{\circ} \mathrm{C}$ para temperaturas mínimas, até o final de 2080. Comparando estes valores aos obtidos do quarto relatório do IPCC (2007), para o cenário A1B, a previsão para a região Nordeste seria de aumento das temperaturas entre 1 a $3{ }^{\circ} \mathrm{C}$, com redução de até $20 \%$ do volume das chuvas. Tais resultados do IPCC são provenientes do ENSEMBLE (médias) de vários modelos, entre os quais os dois aqui discutidos, embora sem nenhum processo de downscaling.

Os resultados para precipitação mostram que o modelo ECHAM5-OM apresenta menos déficit de precipitação na área norte da região Nordeste, inclusive com duas estações do Ceará, Crateús e Quixeramobim, com diferenças positivas em relação ao período 1961-1990.
Isso não acontece no modelo HadGEM2-ES, com precipitações no norte do Nordeste variando entre $200 \mathrm{~mm}$ e $600 \mathrm{~mm}$ a menos do que em relação a 1961-1990. No restante da região, principalmente para o Estado da Bahia, os dois modelos apontam déficits significativos.

Para o cenário A2, foi possível trabalhar apenas com o modelo ECHAM5-OM. O modelo HadGEM2-ES não disponibiliza saídas para este cenário, apenas para os cenários $\mathrm{A} 1$ e A1B, e cenários $\mathrm{B} 1$ e B2, não explorados na pesquisa. A Fig. $8(\mathrm{a}, \mathrm{b}, \mathrm{c})$ mostra os resultados obtidos com o modelo ECHAM5-OM para a precipitação, temperaturas máximas e mínimas. Os resultados mostram que este cenário indica, em média das 23 estações, uma redução de $-26,40 \%$ da precipitação, e aumentos de $1,2{ }^{\circ} \mathrm{C}$ para temperaturas máximas, e $1,3{ }^{\circ} \mathrm{C}$ para temperaturas mínimas, até o final de 2080. Tais valores, um pouco mais brandos que os obtidos para o cenário $\mathrm{A} 1 \mathrm{~B}$, contradizem do que poderia ser esperado de acordo com o relatório do IPCC (2007), que aponta o cenário A2 mais intenso que o cenário $\mathrm{A} 1 \mathrm{~B}$, com maiores déficits de precipitação e maior elevação das temperaturas. Pode-se perceber que os resultados dos dois cenários, A1B e A2 do modelo ECHAM5$\mathrm{OM}$, são muito parecidos.

Resultados similares de redução de precipitação e aumento das temperaturas foram encontrados para Recife por Costa et al. (2020) para a cidade de Recife com os mesmos MCGs e cenários. Os resultados estão de acordo com o exposto em Marengo et al. (2016), que mostram por meio de projeções climáticas futuras que as secas no NEB devem se intensificar até o fim do século XXI. 

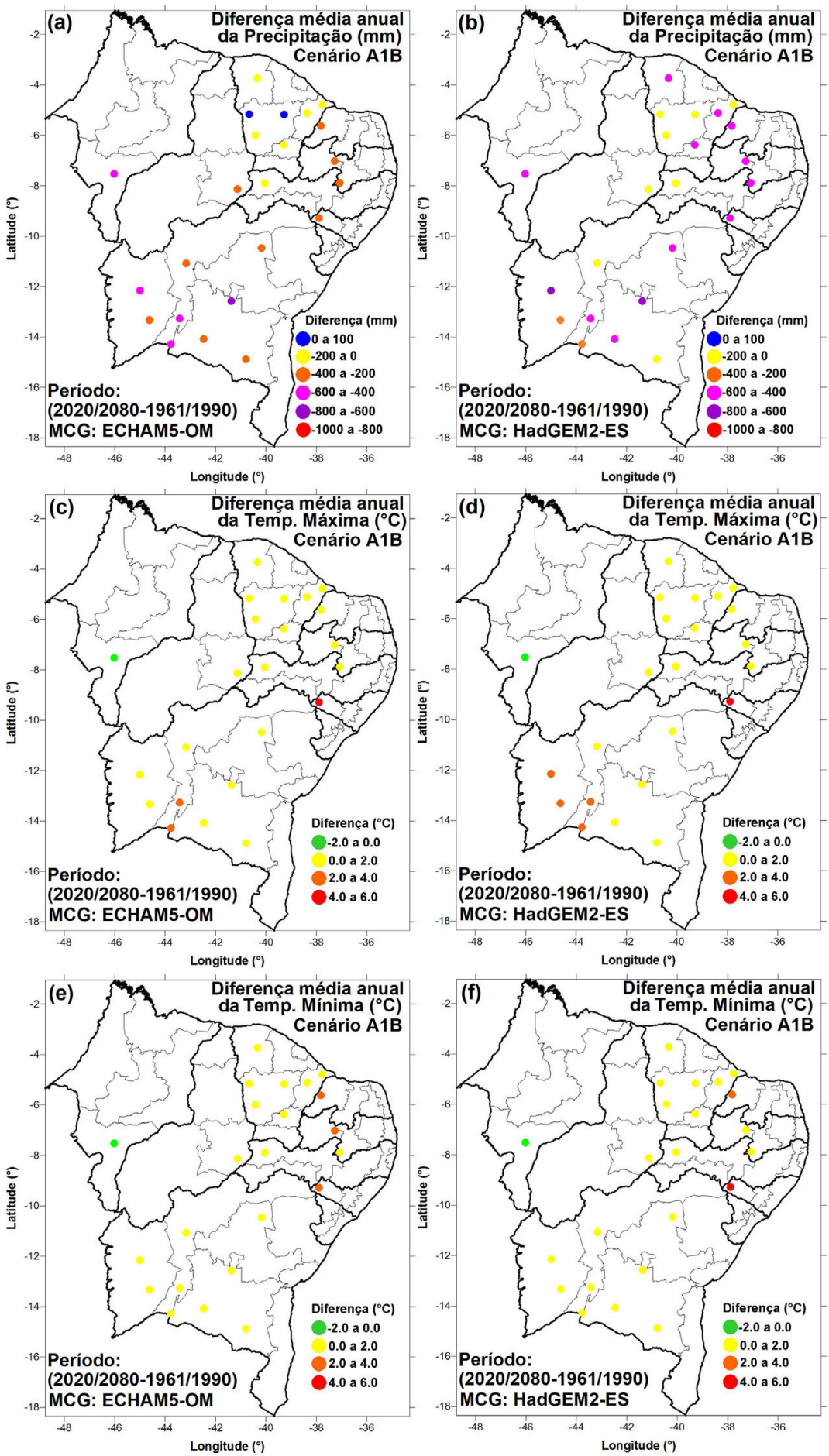

Figura 7 - Diferenças médias anuais da precipitação para 2020-2080, dos modelos ECHAM5-OM (a) e HadGEM2-ES (b) com as médias 1961-1990. O mesmo para temperaturas máximas (c) e (d), e temperaturas mínimas, (e) e (f). Todos os resultados para o cenário A1B.

Assad et al. (2012), avaliaram a redução das áreas de baixo risco climático para o cultivo do algodão herbáceo no Brasil, ante as mudanças climáticas dos cenários A2 e B2, entre 2010 e 2040 . O Nordeste foi a região que apresentou maior redução, em torno de $15 \%$ em 30 anos, das áreas aptas ao cultivo, sob o cenário A2. Os resultados aqui gerados indicam, para o horizonte de 2020 a 2080 , redução significativa das chuvas, principalmente no centro-sul da região Nordeste, envolvendo toda a Bahia, que hoje responde por grande parte da produção nacional. $\mathrm{O}$ aumento da temperatura na maior parte das estações se situa entre $0{ }^{\circ} \mathrm{C}$ e $2{ }^{\circ} \mathrm{C}$, enquanto a precipitação projetada 


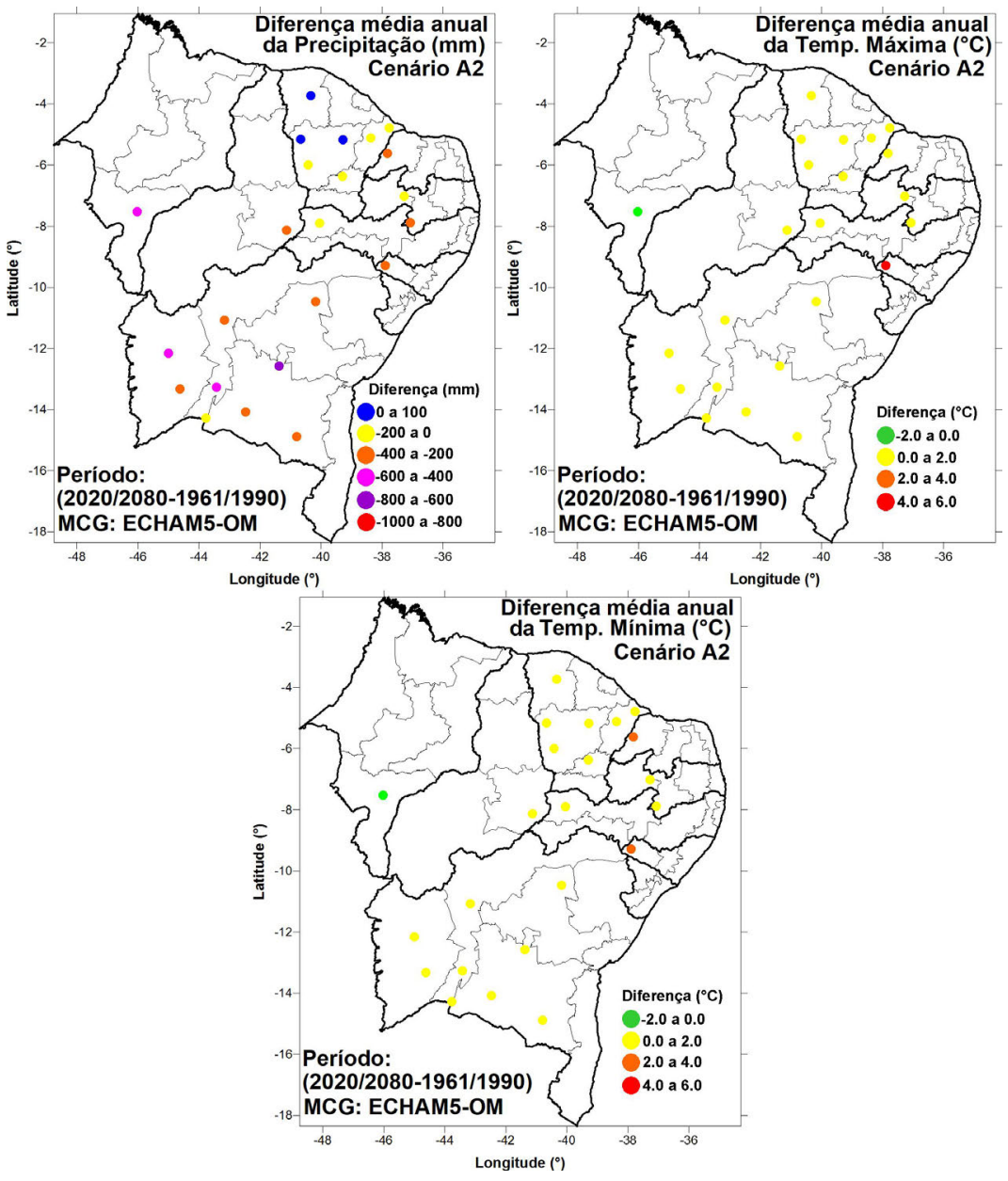

Figura 8 - Mesmo que a Fig. 7, mas apenas para o modelo ECHAM5-OM e cenário A2.

em algumas estações do oeste baiano, por exemplo, poderá ter decréscimo de 400 a $800 \mathrm{~mm}$ do seu total anual. Esta projeção, se confirmada, devera impactar negativamente o cultivo do algodão na região, pois a faixa de temperaturas ótimas para o desenvolvimento do algodão, entre $18{ }^{\circ} \mathrm{C}$ e $30{ }^{\circ} \mathrm{C}$, poderá ser ultrapassada e a quantidade ótima de precipitação, entre 500 e $1500 \mathrm{~mm}$, poderá não ser atingida em muitas safras.

\subsection{Cenários futuros da evapotranspiração potencial}

Como resultado principalmente do aumento das temperaturas, foi observada uma tendência de aumento da ETP, para os dois cenários dos dois modelos, entre 2020 a 2080. Resultados das estimativas diárias para quatro estações são mostradas na Fig. 9, apenas para o cenário A1B para Barra (BA), Monteiro (PB), Patos (PB) e Sobral (CE). Nos gráficos, os valores diários estimados para o período futuro são confrontados com a média diária dos dados observados entre 1961 e 1990, permitindo observar a elevação dos valores de ETP ao longo dos anos de acordo com a reta de tendência linear traçada aos valores calculados. Este resultado é esperado de acordo com estudos que projetam mudanças na taxa de aridez em regiões semiáridas, incrementadas pela redução das chuvas e aumento da ETP (Lin et al., 2016).

\subsection{Cenários futuros da produtividade do algodão}

A partir dos cenários gerados de precipitação e ETP para cada município estudado, foi calculada a penalização, ou percentual de perda de produtividade, no período de 2001 a 2011 com dados meteorológicos observados, permitindo calibrar um modelo agrometeorológico que possibilita estimar tanto a penalização da cultura por déficit hídrico, como também transformar esta penalização em estimativa da produção, em kg/ha (Parte I).

A Tabela 1 mostra a penalização estimada para o período 2020-2080 para os cenários A1B e A2 do modelo ECHAM5-OM, e A1B do HadGEM2-ES, comparada à penalização média calculada com dados observados do período 2001-2011. Os resultados mostram o aumento da 

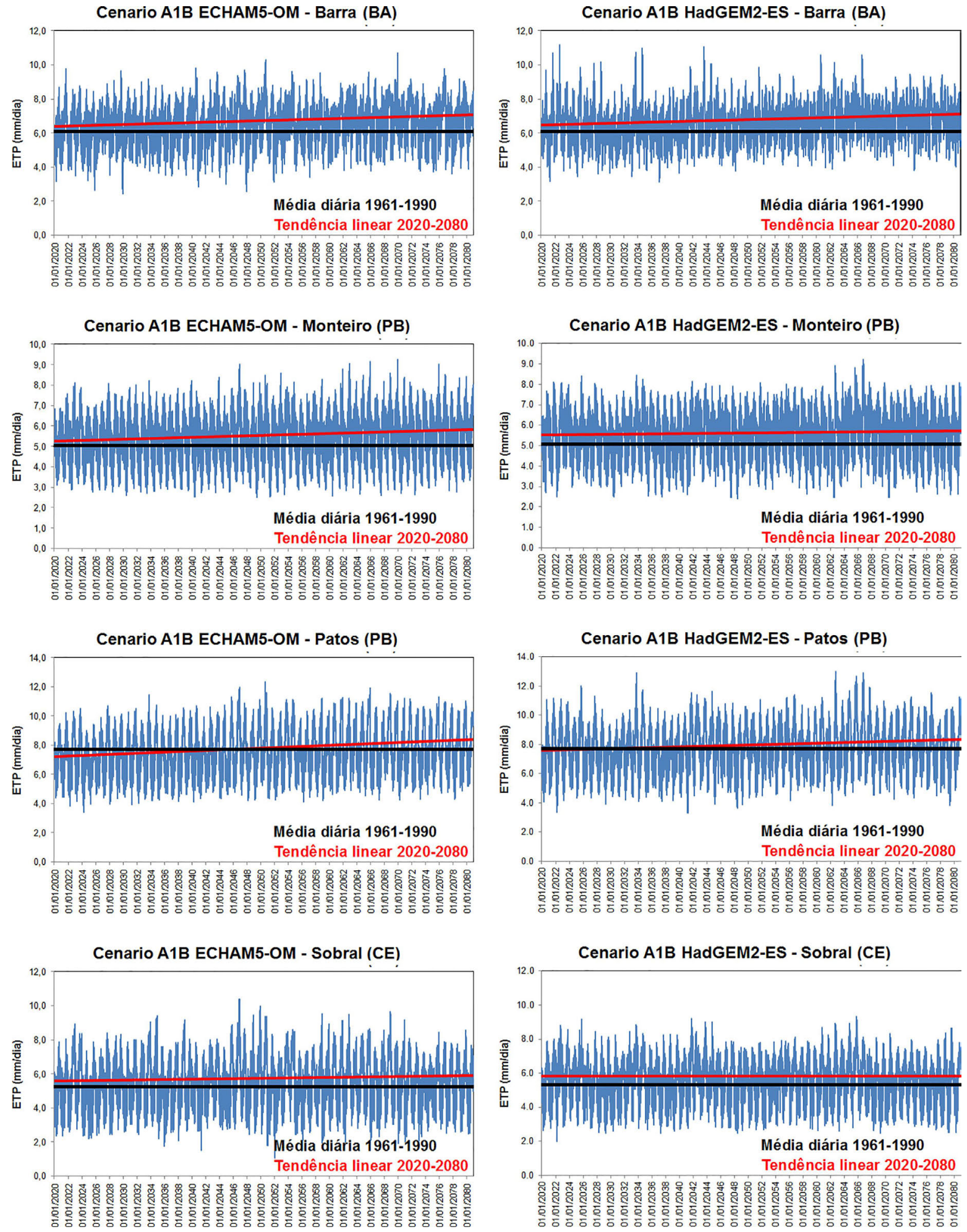

Figura 9 - Evolução da ETP diária, em mm/dia, entre 2020 e 2080 para o cenário A1B dos modelos ECHAM5-OM e HadGEM2-ES, para as estações de Barra (BA), Monteiro (PB), Patos (PB) e Sobral (CE). A linha preta corresponde ao valor médio diário da ETP em 1961-1990, e a linha vermelha corresponde a linha de tendência do período 2020-2080.

penalização por déficit hídrico, projetada pelos cenários futuros para o algodão.
A Fig. 10 apresenta, para oito das 23 estações analisadas, a tendência de aumento do percentual de perda da 
Tabela 1 - Penalização média obtida com dados observados no período 2001-2011 versus valores médios da penalização obtida com os cenários A1B e A2 do modelo ECHAM5-OM, e com o cenário A1B do modelo HadGEM2-ES, para o período 2020-2080.

\begin{tabular}{|c|c|c|c|c|}
\hline Estação & $\begin{array}{c}\text { Penalização Média Obser- } \\
\text { vada (\%) de 2001-2011 }\end{array}$ & $\begin{array}{c}\text { Cenário A1B-ECHAM5- } \\
\mathrm{OM}(\%): 2020-2080\end{array}$ & $\begin{array}{c}\text { Cenário A1B- HadGEM2- } \\
\text { ES (\%): 2020-2080 }\end{array}$ & $\begin{array}{c}\text { Cenário A2- ECHAM5- } \\
\text { OM (\%): 2020-2080 }\end{array}$ \\
\hline Água Branca & 18,0 & 33,7 & 43,7 & 32,6 \\
\hline Apodi & 29,7 & 48,7 & 53,5 & 47,9 \\
\hline Balsas & 18,7 & 42,4 & 46,3 & 42,3 \\
\hline Barra & 42,7 & 51,9 & 47,5 & 49,4 \\
\hline Barreiras & 29,2 & 44,5 & 47,0 & 43,8 \\
\hline B. J. da Lapa & 35,8 & 48,2 & 51,2 & 47,0 \\
\hline Caetité & 38,9 & 47,5 & 47,8 & 45,5 \\
\hline Carinhanha & 39,1 & 48,1 & 44,5 & 40,5 \\
\hline Correntina & 32,7 & 42,5 & 40,1 & 41,7 \\
\hline Crateús & 35,8 & 35,1 & 48,1 & 36,2 \\
\hline Iguatu & 31,7 & 42,4 & $\mathbf{5 0 , 9}$ & 41,1 \\
\hline Jaguaruana & 33,5 & 40,6 & 40,5 & 53,4 \\
\hline Lençóis & 35,4 & 45,1 & 49,9 & 43,2 \\
\hline Monteiro & 37,4 & 55,4 & 60,3 & 54,9 \\
\hline Morada Nova & 33,5 & 41,2 & 53,4 & 42,0 \\
\hline Ouricuri & 43,5 & 53,9 & 58,6 & 53,2 \\
\hline Patos & 24,1 & 55,1 & 57,8 & 53,8 \\
\hline Paulistana & 41,6 & 54,3 & 58,1 & 52,8 \\
\hline Quixeramobim & 31,9 & 40,2 & 50,8 & 41,8 \\
\hline S. do Bonfim & 36,6 & 50,0 & 54,5 & 47,5 \\
\hline Sobral & 24,1 & 34,0 & 45,8 & 34,3 \\
\hline Tauá & 39,6 & 49,1 & 56,1 & 48,0 \\
\hline V. da Conquista & 35,1 & 45,0 & 46,3 & 43,9 \\
\hline
\end{tabular}

cultura do algodão entre 2020 e 2080, para os diferentes cenários dos modelos. Com a diminuição da precipitação projetada para o futuro e aumento da ETP, há tendência significativa de que esta cultura tenha maior probabilidade de perda em sua produtividade. A linha horizontal em cada gráfico representa a penalização média observada em cada município de 2001 a 2011. Os resultados da Fig. 10 indicam uma interessante característica, que é uma perceptível tendência de aumento mais significativa a partir de 2050, podendo-se destacar mais facilmente isto em Monteiro (PB), Ouricuri (PE), Paulistana (PI) e Correntina (BA).

Uma aproximação final para avaliar a perda de produtividade do algodão herbáceo na região Nordeste é mostrada na Fig. 11, sendo projetadas a produtividade média anual do período 2020-2080 dos dois cenários climáticos obtidos com o modelo ECHAM5-OM e do cenário climático obtido com o modelo HadGEM2-ES, em kg/ha. Para chegar a este resultado, foram tomadas as produtividades médias obtidas com dados observados do período 2001-2011, mostradas na Parte I desta pesquisa, e estimadas as dos modelos com base nesta média observada e na penalização média estimada pelos mesmos para 20202080. O resultado mostra claramente que a perda de pro- dutividade se acentua quanto mais produtivo seja o município.

\section{Conclusões}

Para 2020 a 2080, em média, o modelo ECHAM5OM prevê redução de $29,88 \%$ da precipitação, com aumentos de $1,3{ }^{\circ} \mathrm{C}$ das temperaturas máximas e $1,4{ }^{\circ} \mathrm{C}$ das temperaturas mínimas, para o cenário A1B. O modelo HadGEM2-ES prevê, em média, redução de $46,87 \%$ da precipitação, e aumento de $1,5^{\circ} \mathrm{C}$ das temperaturas máximas e $1,3{ }^{\circ} \mathrm{C}$ das temperaturas mínimas, para o cenário A1B. O modelo ECHAM5-OM prevê redução de 26,40\% da precipitação, com aumentos de $1,2^{\circ} \mathrm{C}$ das temperaturas máximas e $1,3{ }^{\circ} \mathrm{C}$ das temperaturas mínimas, para o cenário $\mathrm{A} 2$.

Prevê-se, para 2020 a 2080, uma redução significativa da produtividade do algodão nos 23 municípios estudados, de acordo com os dados gerados com os cenários climáticos futuros A1B e A2, dos modelos ECHAM5-OM e HadGEM2-ES. Este resultado é fruto direto da diminuição da precipitação prevista para o período, assim como do aumento da ETP, se levarmos em consideração apenas o fator clima como condicionante da produtividade. 
Estimativa de Perdas - Balsas (BA)

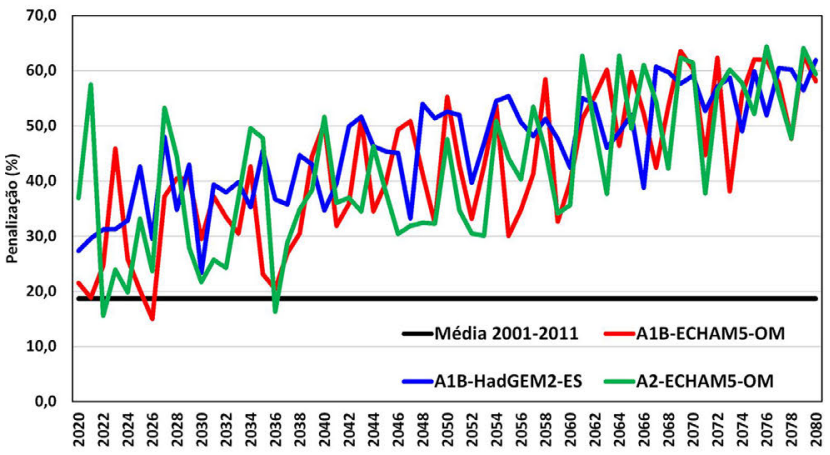

Estimativa de Perdas - Apodi (RN)

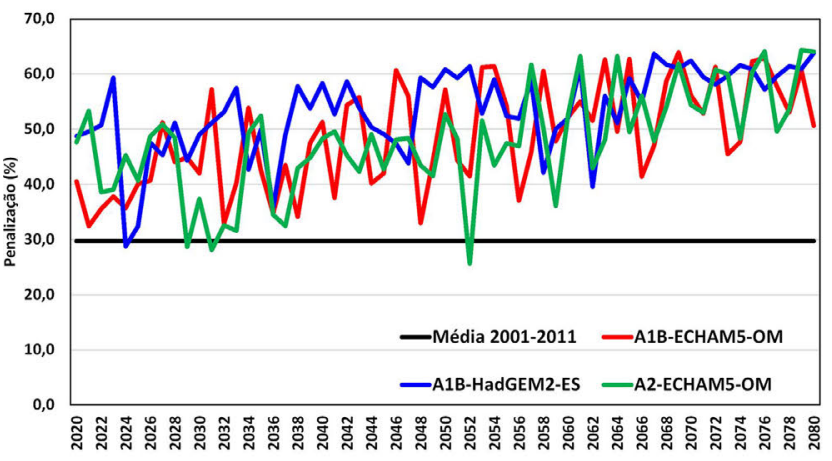

Estimativa de Perdas - Monteiro (PB)

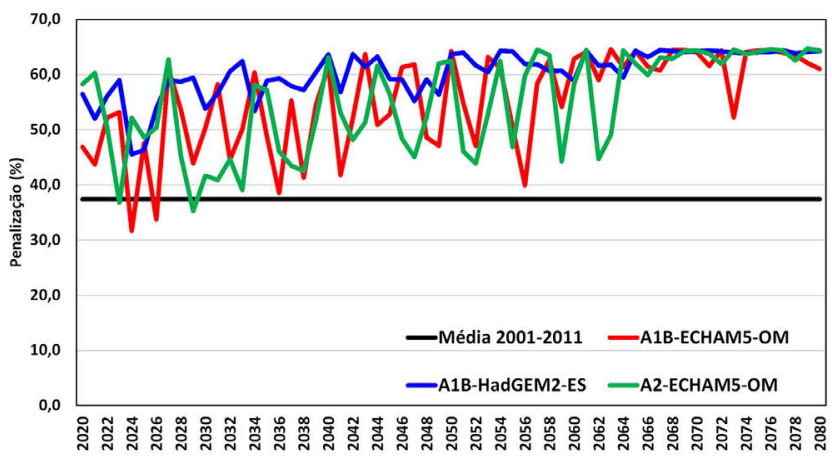

Estimativa de Perdas - Água Branca (AL)

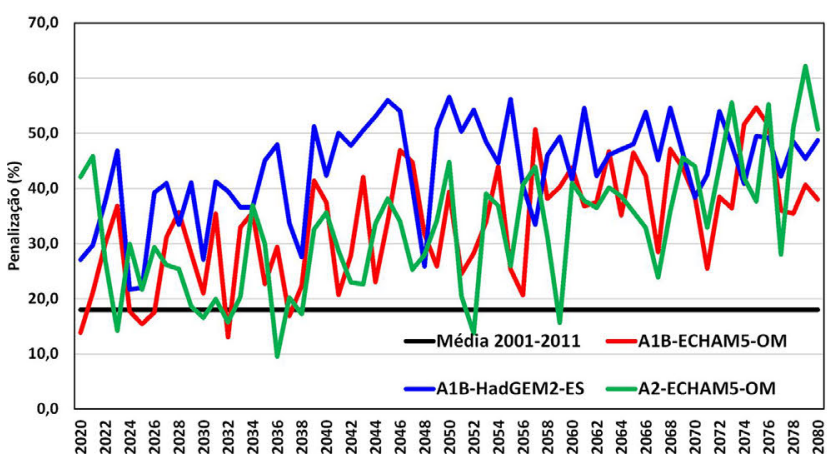

Estimativa de Perdas - Paulistana (PI)

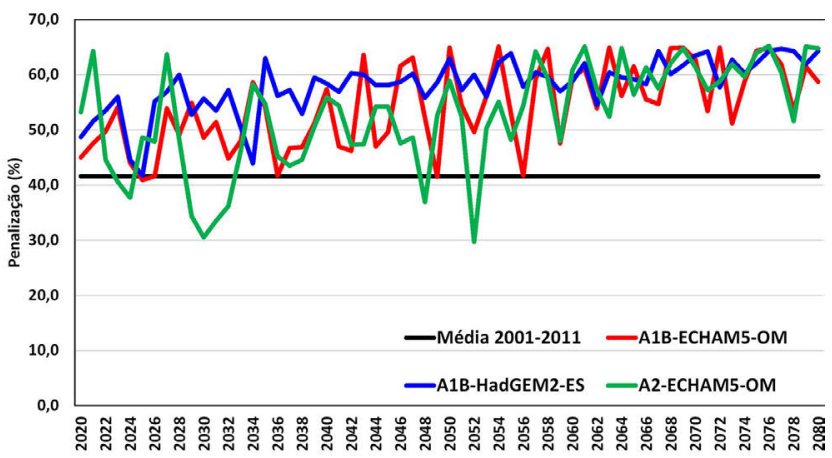

Estimativa de Perdas - Quixeramobim (CE)

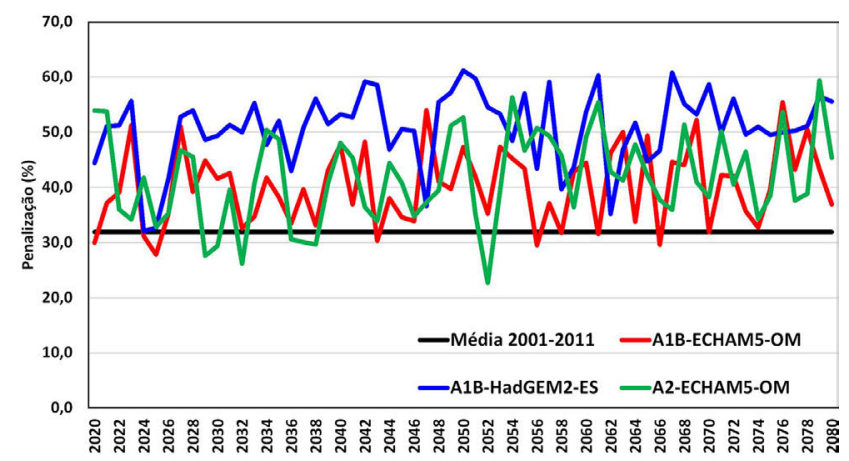

Estimativa de Perdas - Ouricuri (PE)

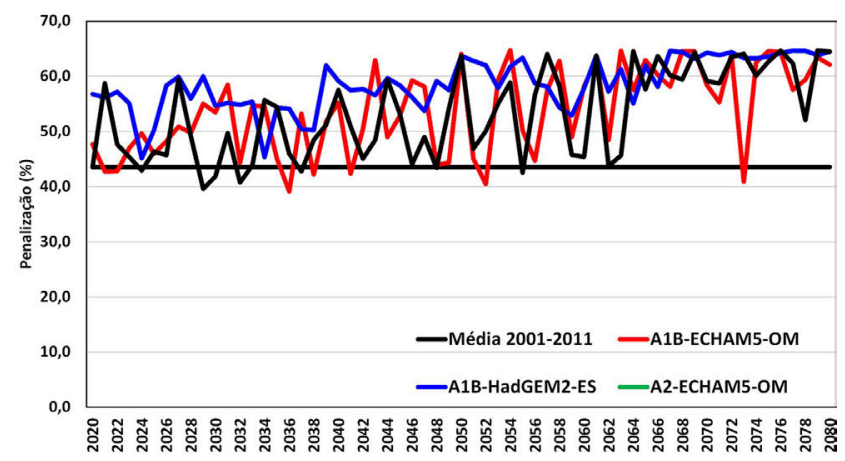

Estimativa de Perdas - Correntina (BA)

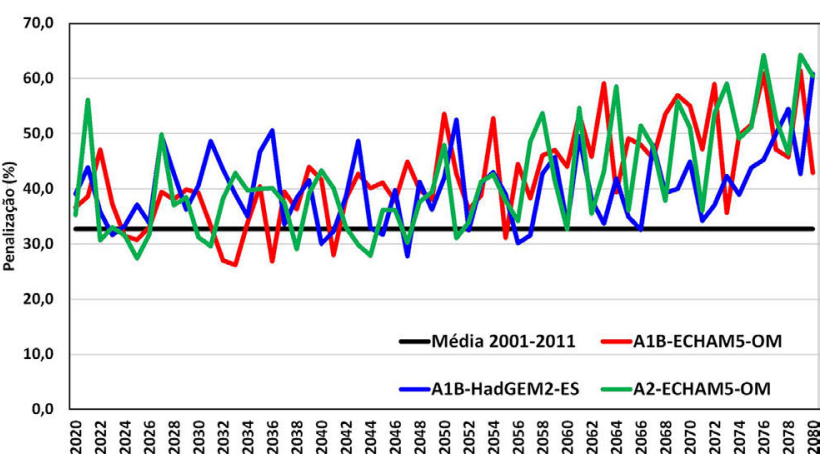

Figura 10 - Estimativa percentual da perda de produtividade do algodão herbáceo para 2020-2080 dos cenários A1B dos modelos ECHAM5-OM (linha vermelha) e HadGEM2-ES (linha azul), e do cenário A2 do modelo ECHAM5-OM (linha verde). A produtividade média observada do período 20012011 é mostrada na linha preta horizontal dos gráficos, para as 23 estações. 


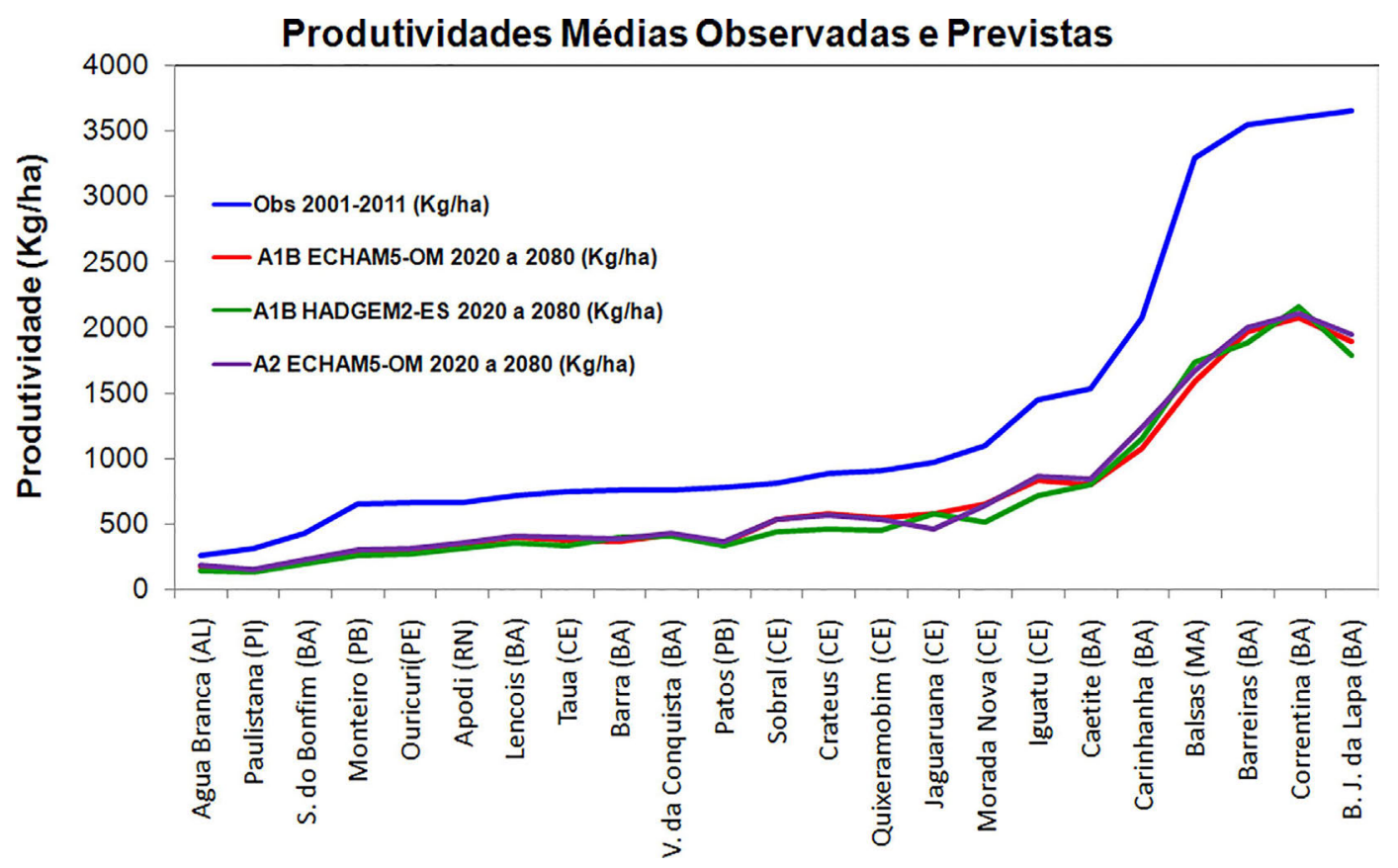

Figura 11 - Produtividades médias do algodão herbáceo (kg/ha) em cada município, entre 2020 e 2080, projetadas para os cenários A1B e A2 do modelo ECHAM5-OM, e A1B do modelo HadGEM2-ES, comparadas com a produtividade média anual observada no período 2001-2011.

Tal redução se mostra mais importante quanto maior a produtividade do município. Locais com produtividade em torno de $3500 \mathrm{~kg} / \mathrm{ha}$ poderão ter seus rendimentos reduzidos a $1700 \mathrm{~kg} / \mathrm{ha}$, aproximadamente, locais com produtividade média de $1500 \mathrm{~kg} / \mathrm{ha}$ poderão ter os rendimentos reduzidos a $750 \mathrm{~kg} / \mathrm{ha}$, aproximadamente, enquanto municípios com produtividade em torno de $750 \mathrm{~kg} / \mathrm{ha}$ poderão ter seus rendimentos reduzidos a $300 \mathrm{~kg} / \mathrm{ha}$, aproximadamente. Isso mostra que os cenários são de redução de aproximadamente metade da produtividade atual.

\section{Agradecimentos}

Os autores agradecem a Coordenação de Aperfeiçoamento de Pessoal de Nível Superior (CAPES) pelo apoio financeiro concedido durante e para a concepção deste estudo.

\section{Referencias}

ALVES, J.M.B.; CAMPOS, J.N.B.; FILHO, F.A.S.; MONCUNNIL, D.F.; SILVA, E.M.; BARBOSA, W.L.; FERREIRA, A.G.; SUN, L.; MOURA, A.D. Uma avaliação preliminar de simulações climáticas de um modelo regional espectral aninhado em um modelo global (ECHAM 4.5) sobre o setor norte da região Nordeste do Brasil (1971-2000). Revista Brasileira de Meteorologia, v. 20, n. 2, p. 191206, 2005.

BARNETT, T.; PREISENDORFER, R. Multifield analog prediction of short-term climate fluctuations using a climate state vector. Journal of Atmospheric Sciences, v. 35, n. 10, p. 1771-1787, 1978.

BELLOUIN N.; BOUCHER, O.; HAYWOOD, J.; JOHNSON, C.; JONES, A.; RAE, J.; WOODWARD, S. Improved representation of aerosols for HadGEM2. Meteorological Office Hadley Centre, Technical Note 73, March 2007.

BENESTAD, R.E. Downscaling precipitation extremes. Theoretical and Applied Climatology, v. 100, n. 1-2, p. 1-21, 2010.

BIAU, G.; ZORITA, E.; VON STORCH, H.; WACKERNAGEL, $\mathrm{H}$. Estimation of precipitation by kriging in the EOF space of the sea level pressure field. Journal of Climate, v. 12, n. 4, p. 1070-1085, 1999.

BRANDS, S.; HERRERA, S.; SAN-MARTIN, D.; GUTIERREZ, J.M. Validation of the ensembles global climate models over southwestern Europe using probability density functions, from a downscaling perspective. Climate Research, v. 48, n. 2-3, p. 145-161, 2011 a.

BRANDS, S.; TABOADA, J.J.; COfiNO, A.S.; SAUTER, T.; SCHNEIDER, C. Statistical downscaling of daily temperatures in the Iberian Peninsula from global climate models: validation and future scenarios. Climate Research, v. 48, n. 2-3, p. 163-176, 2011 b.

BRANDS, S.; GUTIERREZ, J.M.; HERRERA, S. On the Use of Reanalysis Data for Downscaling. Journal of Climate, v. 25, n. 7, p. 2517-2526, 2012.

CABRAL JÚNIOR, J.B.; SILVA, C.M.S.; ALMEIDA, H.A.; BEZERRA, B.G.; SPYRIDES, M.H.C. Detecting linear trend of reference evapotranspiration in irrigated farming areas in Brazil's semiarid region. Theoretical and Applied Climatology, v. 138, n. 1-2, p. 215-225, 2019.

COLLINS, W. J.; BELLOUIN, N.; DOUTRIAUX-BOUCHER, M.; GEDNEY, N.; HINTON, T. C.; JONES, D.; LIDDI- 
COAT, S.; MARTIN, G.; OCONNOR, F.; RAE, J.; SENIOR, C.; TOTTERDELL, I.; WOODWARD, S. Evaluation of the HadGEM2 model. Meteorological Office Hadley Centre, Technical Note 74, 2008.

COLLINS, M.; KNUTTI, R.; ARBLASTER, J.; DUFRESNE, J.L.; FICHEFET, T.; FRIEDLINGSTEIN, P.; GAO, X.; GUTOWSKI, W.J.; JOHNS, T.; KRINNER, G.; SHONGWE, M.; TEBALDI, C.; WEAVER, A.J.; WEHNER, M. Long-term climate change: Projections, commitments and irreversibility. In: Climate Change 2013: The Physical Science Basis. Contribution of Working Group I to the Fifth Assessment Report of the Intergovernmental Panel on Climate Change, pp. 1029-1136, 2013.

COSTA, R.L.; SILVA, F.D.S.; SARMANHO, G.F.; LUCIO, P.S. Imputação Multivariada de Dados Diários de Precipitação e Análise de Índices de Extremos Climáticos. Revista Brasileira de Geografia Física, v. 5, n. 3, p. 661-675, 2012.

COSTA, R.L.; BAPTISTA, G.M.M.; GOMES, H.B.; SILVA, F.D.S.; ROCHA JÚNIOR, R.L.; SALVADOR, M.A.; HERDIES, D.L. Analysis of climate extremes indices over northeast Brazil from 1961 to 2014. Weather and Climate Extremes, v. 28, p. 100254, 2020.

COSTA, R.L.; GOMES, H.B.; SILVA, F.D.S.; ROCHA JÚNIOR, R.L. Downscale of future climate change scenarios applied to Recife-PE. Journal of Hyperspectral Remote Sensing, v. 9, n. 6, p. 361-372, 2020.

CUBASCH, U.; VON STORCH, H.; WASZKEWITZ, J. ZORITA, E. Estimates of climate changes in southern Europe using different downscaling techniques. Climate Research, v. 7, n. 2, p. 129-149, 1996.

FLATO, G.; MAROTZKE, J.; ABIODUN, B.; BRACONNOT, P., CHOU, S.C.; COLLINS, W.; COX, P.; DRIOUECH, F.; EMORI, S.; EYRING, V.; FOREST, C.; GLECKLER, P.; GUILYARDI, E.; JAKOB, C.; KATTSOV, V.; REASON, C.; RUMMUKAINEN, M. Evaluation of climate models. In: Climate Change 2013: The Physical Science Basis. Contribution of Working Group I to the Fifth Assessment Report of the Intergovernmental Panel on Climate Change, pp. 741-882, 2013.

FRICH, P.; ALEXANDER, L.V.; DELLA-MARTA, P.; GLEASON, G.; HAYLOCK, M.; KLEIN TANK, A.M.G.; PETERSON, T. Observed coherent changes in climatic extremes during the second half of the century. Climate Research, v. 19, n. 3, p. 193-212, 2002.

GHIL, M. Natural Climate Variability. in: The Earth system: physical and chemical dimensions of global environmental change. Michael C MACCRACKEN, M.C.; PERRY, J.S. (eds) In Encyclopedia of Global Environmental Change, v. 1, p. 544-549, 2002.

GOMEZ, R.A.Q. Trends of Maximum and Minimum Temperatures in Northern South America. Journal of Climate, v. 16, n. 7, p. 2104-2112, 1999.

GREVE, P.; ORLOWSKY, B.; MUELLER, B.; SHEFFIELD, J.; REICHSTEIN, M.; SENEVIRATNE, S.I. Global assessment of trends in wetting and drying over land. Nature Geoscience, v. 7, n. 10, p. 1-6, 2014. http://dx.doi.org/ 10.1038 /ngeo 2247

GUTIÉRREZ, J.M.; SAN-MARTIN, D.; BRANDS, S.; MANZANAS, R.; HERRERA, S. Reassessing statistical down- scaling techniques for their robust application under climate change conditions. Journal of Climate, v. 26, n. 1, p. 171-188, 2013.

GUTZLER, D.S.; ROBBINS, T.O. Climate variability and projected change in the western United States: regional downscaling and drought statistics. Climate Dynamics, v. 37, n. 5-6, p. 835-849, 2011.

HARTMANN, D.L.; KLEIN-TANK, A.M.G.; RUSTICUCCI, M.; ALEXANDER, L.V.; BRONNIMANN, S.; CHARABI, Y.; DENTENER, F.J.; DLUGOKENCKY, E.J.; EASTERLING, D.R.; KAPLAN, A.; SODEN, B.J.; THORNE, P.W.; WILD, M.; ZHAI, P.M. Observations: Atmosphere and surface. In: Climate Change 2013: The Physical Science Basis. Contribution of Working Group I to the Fifth Assessment Report of the Intergovernmental Panel on Climate Change [Stocker, T.F., D. Qin, G.-K. Plattner, M. Tignor, S.K. Allen, J. Boschung, A. Nauels, Y. Xia, V. Bex and P.M. Midgley (eds.)]. Cambridge University Press, Cambridge, United Kingdom and New York, NY, USA, p. 159-254, 2013.

HAYLOCK, M.R.; PETERSON, T.C.; ALVES, L.M.; AMBRIZZI, T.; ANUNCIAÇÃO, Y.M.T.; BAEZ, J.; BARROS, V.R.; BERLATO, M.A.; BIDEGAIN, M.; CORONEL, G.; CORRADI, V.; GARCIA, V.J.; GRIMM, A.M.; KAROLY, D.; MARENGO, J.A.; MARINO, M.B.; MONCUNILL, D.F.; NECHET, D.; QUINTANA, J.; REBELLO, E.; RUSTICUCCI, M.; SANTOS, J.L.; TREBEJO, I.; VINCENT, L.A. Trends in Total and Extreme South American Rainfall in 1960-2000 and Links with Sea Surface Temperature. Journal of Climate, v. 19, n. 8, p. 1490-1512, 2006.

HEWITSON B.C.; CRANE, R.G. Climate downscaling: techniques and application. Climate Research, v. 7, n. 29, p. 8595, 1996.

HUANG, G.; PAES, A.T. Posso usar o teste t-Student quando preciso comparar três ou mais grupo? Einstein: Educação Continuada em Saúde, v. 7, n. 2, p. 63-64, 2009.

JONES, R.G.; NOGUER, M.; HASSEL, D.C.; HUDSON, D.; WILSON, S.S.; JENKINS, G.J.; MITCHELL, J.F.B. Generating high resolution climate change scenarios using PRECIS. Meteorological Office Hadley Centre. Exeter, UK, 40p. 2004.

KALNAY, E., KANAMITSU, M.; KISTLER, R.; COLLINS, W.; DEAVEN, D.; GANDIN, L.; IREDELL, M.; SAHA, S.; WHITE, G.; WOOLLEN, J.; ZHU, Y.; CHELLIAH, M.; EBISUZAKI, W.; HIGGINS, W.; JANOWIAK, J.; MO, K.C.; ROPELEWSKI, C.; WANG, J.; LEETMAA, A.; REYNOLDS, R.; JENNE, R.; JOSEPH, D. The NCEP/ NCAR 40-Year Reanalysis Project. Bulletin of the American Meteorological Society, v. 77, n. 3, p. 437-471, 1996.

KRUIZINGA, S.; MURPHY, A.H. Use of an Analogue Procedure to Formulate Objective Probabilistic Temperature Forecasts in the Netherlands. Monthly Weather Review, v. 111, n. 11, p. 2244-2254, 1983.

KÜRBIS, K.; MUDELSEE, M.; TETZLAFF.; BRÁZDIL, R. Trends in extremes of temperature, dew point, and precipitation from long instrumental series from central $\mathrm{Eu}-$ rope. Theoretical and Applied of Climatology, v. 98, n. 1, p. 187-195, 2009. 
LIN, L.; GETTELMAN, A.; FU, Q.; XU, Y. Simulated differences in 21 st century aridity due to different scenarios of greenhouse gases and aerosols. Climatic Change, v. 146, n. 3-4, p. 407-422, 2018.

LORENZ, E.N. Atmospheric predictability as revealed by naturally occurring analogues. Journal of the Atmospheric Sciences, v. 26, n. 4, p. 636-646, 1969.

MARENGO, J.A.; JONES, R.; ALVES, L.M.; VALVERDE, M.C. Future change of temperature and precipitation extremes in South America as derived from the PRECIS regional climate modeling system. International Journal of Climatology, v. 29, n. 15, p. 2241-2255, 2009.

MARENGO, J.A.; TORRES, R.R.; ALVES, L.M. Drought in Northeast Brazil-past, present, and future. Theoretical and Applied Climatology, v. 129, n. 3-4, p. 1189-1200, 2016.

MARSLAND, S.J.; HAAK, H.; JUNGCLAUS, J.H.; LATIF, M.; ROESKE, F. The Max-Planck-Institute global ocean/sea ice model with orthogonal curvilinear coordinates. Ocean Modelling, v. 5, n. 2, p. 91-127, 2003.

MITCHELL, T.D.; HULME, M. Predicting regional climate change: living with uncertainty. Progress in Physical Geography, v. 23, n. 1, p. 57-78, 1999.

NAKICENOVIC, N.; ALCAMO, J.; DAVIS, G.; DE VRIES, B.; FENHANN, J.; GAFFIN, S.; GREGORY, K.; GRÜBLER, A.; JUNG, T.Y.; KRAM, T.; LA ROVERE, E.L.; MICHAELIS, L.; MORI, S.; MORITA, T.; PEPPER, W.; PITCHER, H.; PRICE, L.; RAIHI, K.; ROEHRL, A.; ROGNER, H.H.; SANKOVSKI, A.; SCHLESINGER, M.; SHUKLA, P.; SMITH, S.; SWART, R.; VAN ROOIJEN, S.; VICTOR, N.; DADI, Z. IPCC: Special Report on Emissions Scenarios, Cambridge University Press, Cambridge, United Kingdom and New York, NY, USA, 2000.

PERKINS, S.E.; PITMAN, A.J.; HOLBROOK, N.J.; McANENEY, J. Evaluation of the AR4 climate models? simulated daily maximun temperature, minimun temperature and precipitation over Australia using Probability Density Functions. Journal of Climate, v. 20, n. 17, p. 4356-4376, 2007.

RADDATZ T.J.; REICK, C.H.; KNORR, W.; KATTGE, J.; ROECKNER, E.; SCHNUR, R.; SCHNITZLER, K-G.; WETZEL, P.; JUNGCLAUS, J. Will the tropical land biosphere dominate the climate-carbon cycle feedback during the twenty first century? Climate Dynamics, v. 29, n. 6 , p. 565-574, 2007.

RASKIN P, MONKS F, RIBEIRO T, VAN VUUREN DP \& ZUREK M. Global scenarios in historical perspective. In: Carpenter S, Pingali P.eds. Millennium ecosystem assessment - scenarios assessment. Island Press, Washington, 2005.

SAMPAIO, G.; DIAS, P.L.S. Evolução dos modelos climáticos e de previsão de tempo e clima. Revista USP, n. 103, p. 41$54,2014$.
SHEFFIELD, J.; WOOD, E.F. Projected changes in drought occurrence under future global warming from multi-model, multi-scenario, IPCC AR4 simulations. Climate Dynamics, v. 31, n. 1, p. 79-105, 2008.

SOLMAN, S.A., NUÑEZ, M.N., CABRÉ, M.F. Regional climate change experiments over southern South America. I: present climate. Climate Dynamics, v. 30, n. 5, p. 533-552, 2008.

SRES - Emissions Scenarios. 2010. A Special Report of IPCC Working Group III. Published for the Intergovernmental Panel on Climate Change, ISBN: 92-9169-113-5.

TIMBAL, B.; DUFOUR, A.; MCAVANEY, B. An estimate of future climate change for western France using a statistical downscaling technique. Climate Dynamics, v. 20, n. 7, p. 807-823, 2003.

TIMBAL, B.; JONES, D.A. Future projections of winter rainfall in southeast Australia using a statistical downscaling technique. Climatic Change, v. 86, n. 1, p. 165-187, 2008.

UPPALA, S.M.; KALLBERG, P.W.; SIMMONS, A.J.; ANDRAE, U.; BECHTOLD, V.C.; FIORINO, M.; GIBSON, J.K.; HASELER, J.; HERNANDEZ, A.; KELLY, G.A.; LI, X.; ONOGI, K.; SAARINEN, S.; SOKKA, N.; ALLAN, R.P.; ANDERSSON, E.; ARPE, K.; BALMASEDA, M.A.; BELJAARS, A.C.M.; VAN DE BERG, L.; BIDLOT, J.; BORMANN, N.; CAIRES, S.; CHEVALLIER, F.; DETHOF, A.; DRAGOSAVAC, M.; FISHER, M.; FUENTES, M.; HAGEMANN, S.; HOLM, E.; HOSKINS, B.J.; ISAKSEN, L.; JANSSEN, P.A.E.M.; JENNE, R.; MCNALLY, A.P.; MAHFOUF, J-F.; MORCRETTE, J.J.; RAYNER, N.A.; SAUNDERS, R.W.; SIMON, P.; STERL, A.; TRENBERTH, K.E.; UNTCH, A.; VASILJEVIC, D.; VITERBO, P.; WOOLLEN, J. The era-40 re-analysis. Quarterly Journal of The Royal Meteorlogical Society, v. 131, n. 612, p. 2961-3012, 2005.

VAN BUUREN, S.; GROOTHUIS-OUDSHOORN, K. MICE: Multivariate Imputation by Chained Equations in R. Journal of Statistical Software, v. 45, n. 3, p. 1-67, 2011.

VAN DEN DOOL, H. Searching for analogs, how long must we wait? Tellus, v. 46, n. 3, p. 314-324, 1994.

ZORITA, E.; HUGHES, J.P.; LETTENMAIER, D.P.; VON $\mathrm{STORCH}, \mathrm{H}$. Stochastic characterization of regional circulation patterns for climate model diagnosis and estimation of local precipitation. Journal of Climate, v. 8, n. 5, p. 1023-1042, 1995.

ZORITA, E.; VON STORCH, H. The analog method as a simple statistical downscaling technique: Comparison with more complicated methods. Journal of Climate, v. 12, n. 8, p. 2474-2489, 1999.

License information: This is an open-access article distributed under the terms of the Creative Commons Attribution License (type CC-BY), which permits unrestricted use, distribution and reproduction in any medium, provided the original article is properly cited. 